\title{
El complejo Arcaico Marcavilca y la movilidad cíclica de las poblaciones tempranas de Chorrillos
}

\author{
Luisa Diaz Arriola*
}

\begin{abstract}
Resumen
Esta es una investigación acerca del "Complejo Marcavilca", que caracterizó el proceso de ocupación cultural en la pendiente sur de! Morro Solar, en el distrito de Chorillos, dentro del sur de la ciudad de Lima. Sobre la base de las evidencias arqueológicas encontradas, se ha propuesto un patrón de movilidad cíclica para las poblaciones tempranas del Morro Solar. Este patrón consistió una estrategia de subsistencia usada por los pescadores-agricultores arcaicos, quienes explotaron los recursos de la costa y valles cercanos, estableciendo una complementariedad económica. Esta estrategia nos ha permitido definir un modelode ocupación para este territorio, correspondiente al Período Arcaico (10,000 a 3,500 a.p.), usualmente caracterizado por la domesticación de plantas y animales en los Andes Centrales.
\end{abstract}

Palabras Claves: Perú, Costa Central, Marcavilca, Período Arcaico, Movilidad Cíclica.

\begin{abstract}
This investigation is about the "Marcavilca Complex", the cultural occupation process identified in the southern slope of the Morro Solar, in the district of Chorrillos, situated in the southern part of Lima, the Peruvian capital. Based on the archeological evidences we have found, a cyclical mobility is proposed for the early populations of the Morro Solar, as a subsistence strategy used by this archaic fishermencultivators which exploited the resources of the shore and nearby valleys, establishing a complementary economy. This strategy' permits us to define an occupation model of this territory, the Peruvian central coast, that corresponds to the Archaic Period (10,000 a 3,500 bP), characterized by the domestication of plants and animals in the Central Andes.
\end{abstract}

Keywords: Perú, central coast, Marcavilca, Archaic period, cyclical mobility.

\footnotetext{
* Docente de la Escuela de Arqueología de la Universidad Nacional Mayor de San Marcos. Correo electrónico: ledaluisa@gmail.com
} 
Introducción

El presente artículo resume la tesis titulada "Estrategias de Ocupación del Litoral Durante el Arcaico Medio y Tardío: El Conchal San Genaro"', elaborada por la suscrita en el año 2005, para optar el grado de Magister en Arqueología Andina, en la Facultad de Ciencias Sociales de la Universidad Nacional Mayor de San Marcos. La citada tesis da cuenta del proceso de ocupación cultural en la ladera sur del Morro Solar del distrito de Chorrillos, el que hemos denominamos "Marcavilca", en concordancia con las fuentes etnohistóricas que señalan este nombre comola denominación más antigua de este estribación ubicada al pie del mar de Chorrillos.

Parte de las evidencias arqueológicas identificadas se registraron en el marco del "Estudio de Evaluación Arqueológica de los Asentamientos Humanos Nueva Caledonia II, San Genaro y 26 de Septiembre". La evaluación se realizó por encargo de la Comisión de Formalización de la Propiedad Informal (COFOPRI), y gracias a sus resultados se logró identificar y establecer la delimitación del área intangible del sitio arqueológico "Conchal San Genaro". Otras evidencias también incorporadas en la tesis corresponden a la información arqueológica recopilada por otros investigadores, quienes trabajaron en la zona a partir de los años 60 del siglo pasado, pero sobre todo a finales de ese siglo.

Los más de $4000 \mathrm{~m}^{2}$ correspondientes al "Conchal San Genaro" presentan una deposición cultural densa y profunda, que en algunos sectores sobrepasa los $2 \mathrm{~m}$ de profundidad, representando una ocupación prolongada en la zona. Esta prolongada ocupación se debió a los ecosistemas próximos existentes, que convirtieron el área en una zona de captación de recursos especial, lo que permitió la subsistencia de las poblaciones arcaicas que constantemente la visitaron y se asentaron en ella.
Consideramos que el conocimiento permanentie y concentrado de distintos contextos arqueológicos arcaicos en toda la ladera sur del Morro Solar, nos han permitido identificar la existencia de un complejo cultural temprano, tanto en términos cronológicos como corológicos, que es necesario investigar. En esta zona, no es extraño encontrar permanentemente las fogatas $y$ estaciones dispersas de las poblaciones arcaicas. A la vez, en las partes bajas de esta ladera se concentiaron en el sitio el Conchal San Genaro, lo que nos dice del establecimiento permanente de los pescadores agricultores tempranos.

El hilo conductor de la tesis gira en torno al tema. de la movilidad o trashumancia de las poblaciones tempranas de Chorrillos, a partir del cual se pudo plantear un modelo de ocupación del territorio estudiado, y proponer el proceso de ocupación cultural identificado. Con ese fin se reali:zó el estudio detallado de los ecosistemas existentes, así como la procedencia de los ecofactos y artefactos recuperados durante nuestras investigaciones. De esta manera no se buscó reconstruir los distintos ecosistemas y zonas de captación utilizados por los pobladores tempranos. Como resultado, proponemos que en la costa central peruana durante el periodo Arcaico estas poblaciones desarrollaron un patrón de movilidad cíclica entre los nichos ecológicos existentes, como una estrategia de subsistencia que se dio en dos ejes, uno longitudinal, a lo largo de la línea costera y, el otro transversal que sigue la línea del valle, junto con sus lomas. De esta manera, no se desarrolló una economía espercializada sólo en los recursos marinos, sino que por el contrario, se desarrolló una economía complementaria entre los recursos del mar y del valle, que les permitió a los pobladores superar las c:arencias de recursos estacionales propios de la ecología de la región o los ocasionados por los paleo-ENSOs. Asimismo, entendemos que en esta estrategia de subsistencia se encuentra una

\footnotetext{
1 Para una comprensión más amplia del tema presentado puede remitirse a la Tésis "Estrategias de Ocupación del Litoral Durante el Arcaico Medio y Tardio: El Conchal San Genaro", UNMSM.
} 
condición especial que sentó las bases para el origen de las sociedades complejas de la región durante el Arcaico Tardio, y que las identificamos plenamente establecidas durante el Arcaico Final.

\section{Aspectos generales del sitio}

El sitio arqueológico denominado "Conchal San Genaro" se localiza en la laciera sur del Morro Solar, a $1.5 \mathrm{~km}$ del mar y dentro de los linderos del A.H. San Genaro, ubicado en el distrito de Chorrillos, provincia y departamento de Lima (Fig. 1). A través del estudio preliminar del sitio, hemos podido determinar su importancia y su relación con el temprano proceso de ocupación de la zona, llevado a cabo por poblaciones de pescadores-agricultores incipientes en los períodos del Arcaico Medio y Tardío. El sitio se encuentra a $1 \mathrm{~km}$ al Este del sitio arqueológico "Chira Villa" (Fig. 2), dentro de las coordenadas geográficas UTM 8'650,990 N y 280,299 E. En la zona intermedia entre estos dos sitios arqueológicos, ahora urbanizada por asentamientos humanos modernos, se han podido observar delgadas concentraciones de ceniza de distribución dispersa y aisladas, que representarían eventos de ocupación de patrón disperso, a modo de pequeñas estaciones en donde se elaboraron fogatas, las que dejaron áreas de quema asociadas al consumo de alimentos (Hudtwalcker 1997, Montoya 1996, Rea 1997). Caracteriza a estas concentraciones la ausencia recurrente de cultígenos, la presencia de instrumentos líticos rudimentarios y el consumo abundante de recursos marinos, especialmente moluscos, entre los que destacan la Mesodesma donacium.

La zona que corresponde al emplazamiento del "Conchal San Genaro" se ubica a 30 msnm, en una pampa arenosa de suave pendiente (Fig. 3), que desciende desde el NE hasta llegar al área agrícola, la que a su vez está delimitada por un pequeño promontorio rocoso ubicado hacia el lado este. Por el lado norte se erige la ladera del Morro Solar que presenta una vegetación de "lo. ma" xerófita (tipo tillanıdsia). El sitio en sí mismo es una extensa área de $4131.05 \mathrm{~m}^{2}$ que cuenta con un perímetro de $253.17 \mathrm{ml}$, y que concentra la superposición de capas de moluscos y espacios de quema que otorgan a toda la superficie arenosa una coloración cenicienta, mezclada con gran cantidad de moluscos fragmentados (Fig. 4). En algunos casos, el yacimiento arqueológico puede alcanzar una profundidad de $2 \mathrm{~m}$ en lo que habría sido el depósito principal. Asimismo, extrañas intrusiones arqueolúgicas en el terreno, cortan los estratos de ocupaciones anteriores configurando una serie de hoyos de $2 \mathrm{~m}$ a $2.5 \mathrm{~m}$ de diámetro de planta circular. El estado de conservación actual del sitio arqueológico es relativamente bueno, teniendo en cuenta los acelerados procesos de urbanización acelerados que se han sucedido en la zona desde la década del 80 del siglo pasado, asi como la falta de evidencias arquitectónicas superficiales que caracterizan a los campamentos abiertos de esta época.

La zona en particular fue muy rica en recursos naturales, debido a los ecosistemas variados y muy próximos allí existentes. Están presentes los ecosistemas de playa arenosa (Villa, Lomo de Corvina), playa rocosa (La Chira, La Herradura, y la Bahia de Chorrillos), las zonas de humedales (Pantanos de Villa), además de los pequeños bosques, ahora desaparecidos por el avance urbano. De otro lado, las cercanas "lomas costeras" ubicadas en los arenales de Villa el Salvador y San Juan, junto con los demás ecosistemas, configuraron una zona de captación de recursos ideal para los antiguos pobladores del área, lo que se evidencia por la densa ocupación cultural identificada tanto en el Conchal San Genaro como en Chira - Villa y alrededores.

Asimismo, la existencia de rutas naturales de tránsito entre la zona del Morro Solar y el valle de Lurín hicieron mas fácil el acceso a la cuenca baja del río Lurín, caracterizada por sus zonas inundables propicias para la agricultura incipiente, asi como por sus áreas de "lomas costeras" ubicadas tanto en terrenos arenosos, 

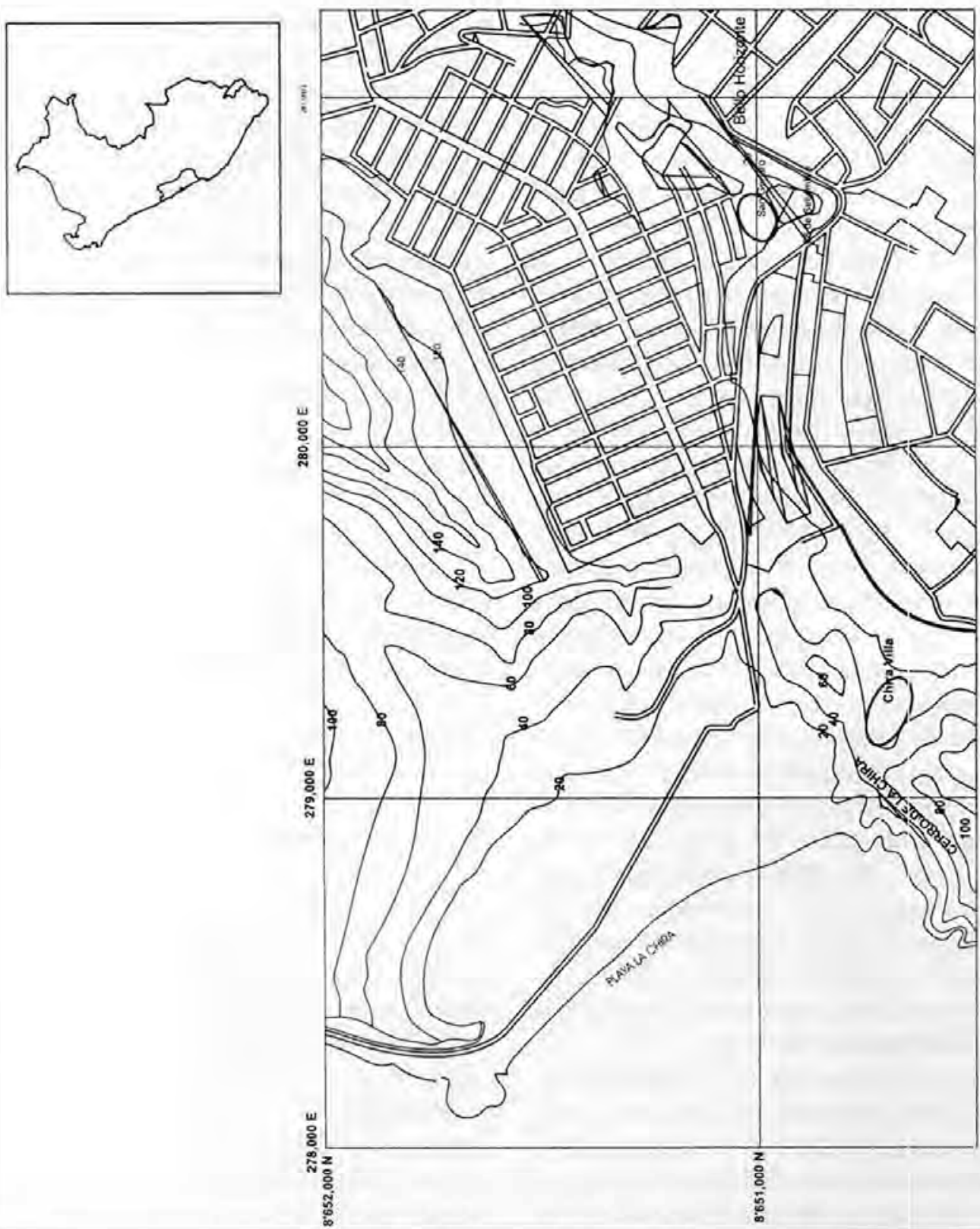

Figura 1. Plano de ubicación del Conchal San Genaro y el sitio Chira-Villa. 


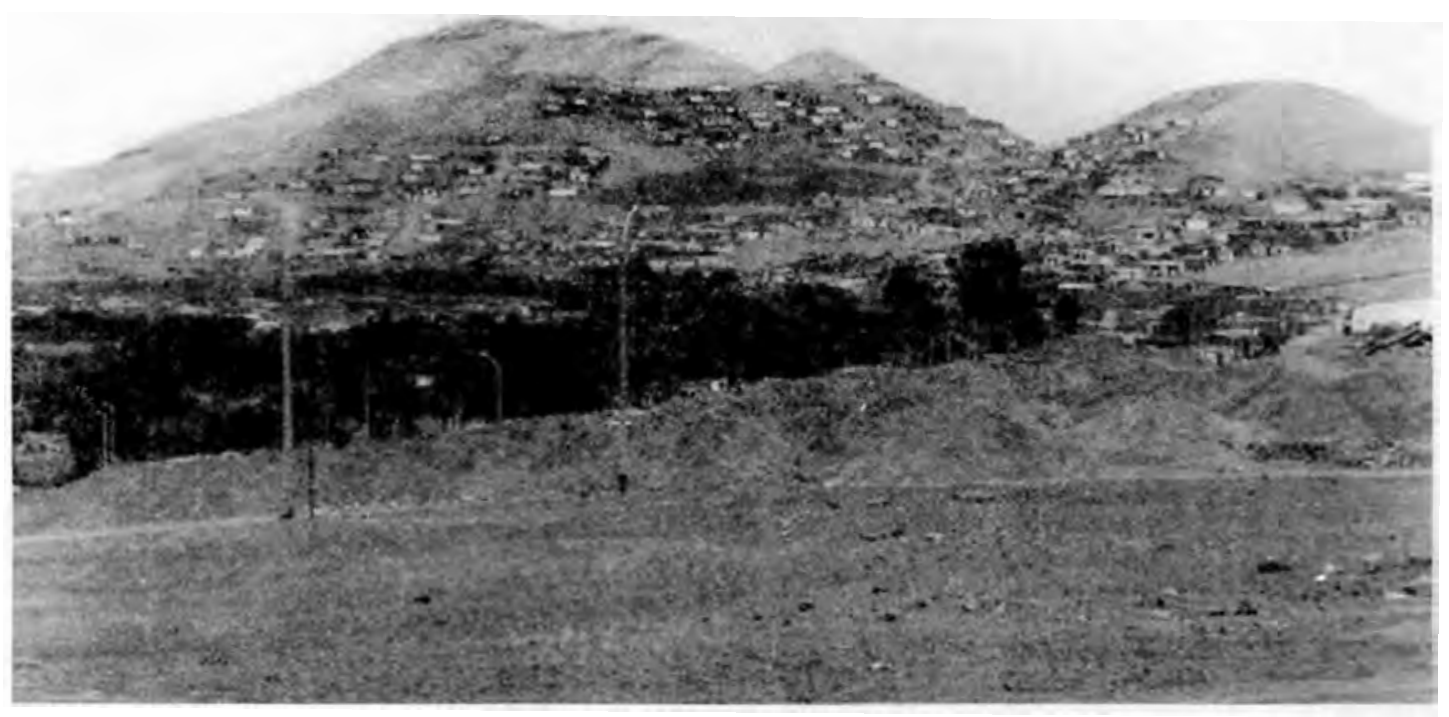

Figura 2. El sitio Chira-Villa visto desde el Conchal San Genaro.

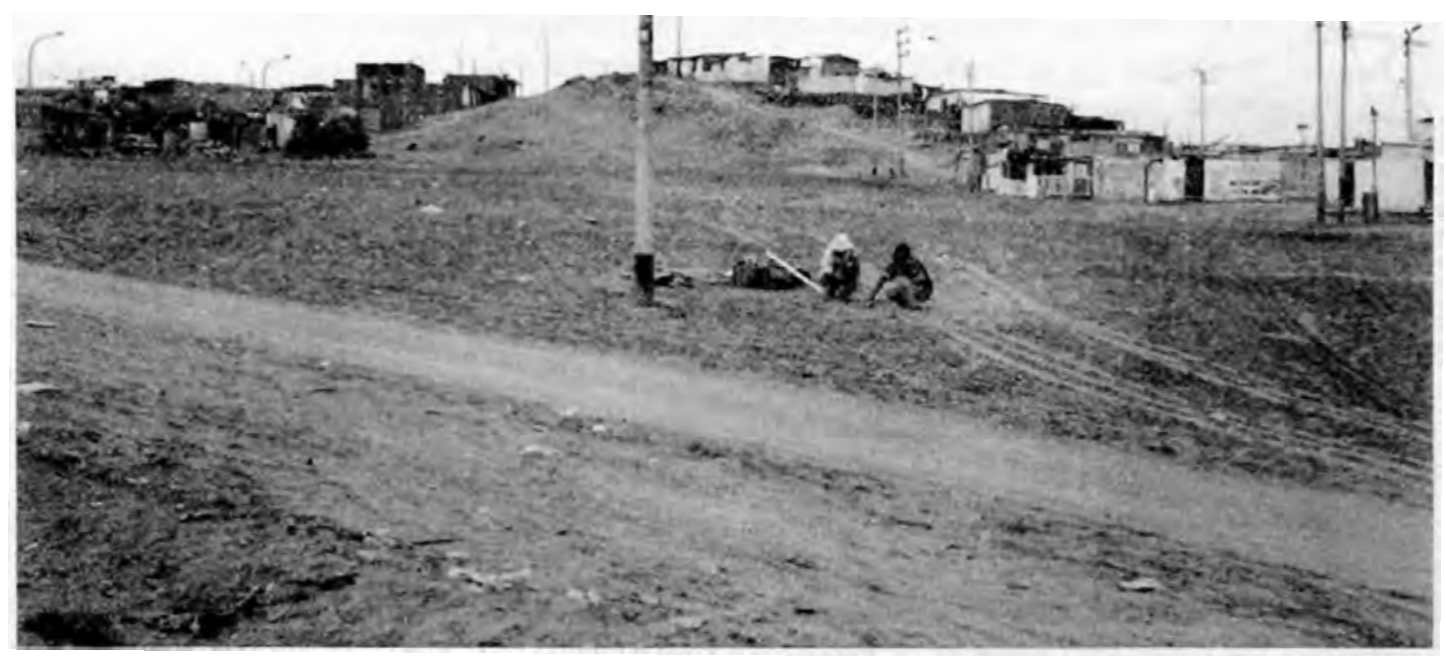

Figura 3. Emplazamiento del Conchal San Genaro donde se observa la suave pendiente de la superficie. 


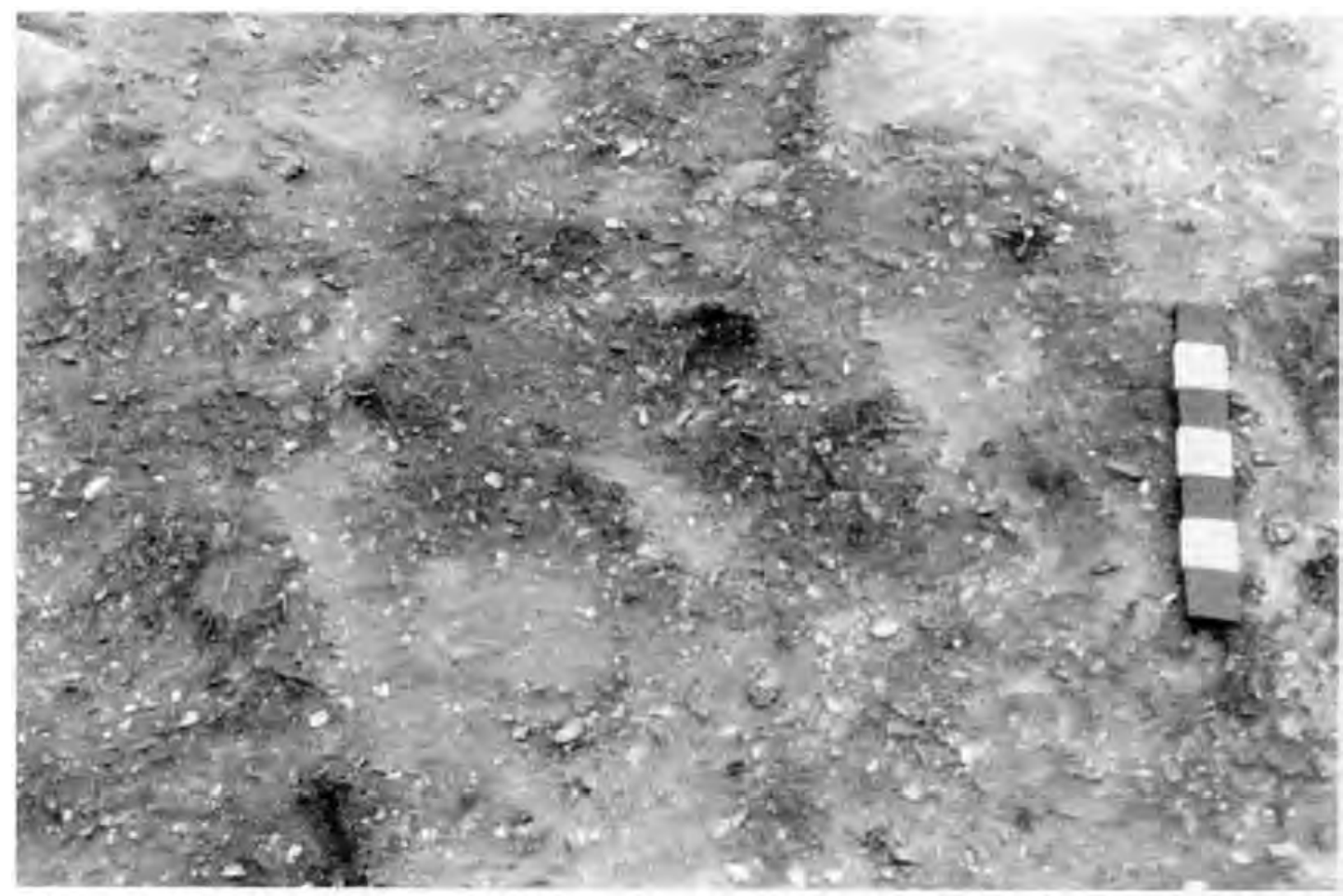

Figura 4. Detalle de la superficie del Conchal San Genaro.

como rocosos y abruptos. Estos últimos se utilizaron como zonas de abrigos y cotos de caza.

\section{Marco referencial de la investigación}

Luego de las primeras investigaciones sobre el hombre temprano en el territorio peruano (Bird 1948, 1949 1985; Willey y Corbett 1952; Engel 1957, 1958, 1963), donde se logró demostrar la existencia de asentamientos precerámicos con arquitectura monumental y domestica distribuidos en toda la costa peruana, mucho más se ha avanzado en el estudio de estas sociedades tempranas. En las décadas posteriores se realizaron otras investigaciones en la región de la costa (costa norte [Talara, Paiján], costa norcentral [Huarmey], costa central [Ancón, Chillón, San Bartolo, Chilca], costa sur [Ilo, Arequipa, Moquegua, Tacna]), y la sierra (Huanuco [Lauricocha], Callejón de Huaylas [Cueva de Guitarrero, Quisquipuncu], Ayacucho, Junín [Pachamachay, Telarmachay, Panaulauca],
Móquegua [Asana] y Tacna [Toquepala]) que han permitieron consolidar la comprensión del periodo. En nuestra zona de investigación (ladera sur del Morro Solar), Lanning (1960) realizó las primeras investigaciones arqueológicas al trabajar en el sitio Chira-Villa, donde logró definir dos fases ocupacionales, una precerámica denominada Villa y la otra denominada Chira con presencia de cerámica inicial. Nuevas investigaciones, a partir de la década del 90 , estuvieron dirigidas a verificar la existencia o ausencia de evidencias arqueológicas en las zonas periféricas a Chira-Villa. Los resultados fueron positivos en los sectores de Colinas de Villa y Nueva Caledonia I (Hudtwalker 1997; Montoya 1996), el ilustre maestro Raúl Haya de la Torre (Rea 1997), Nueva Caledonia II y San Genaro (Díaz 1999; Medina 2000) e Ilustre Maestro Raúl Haya de la Torre (Rea 1997), donde se identificó el "Conchal San Genaro", pero fundamentalmente se encontraron evidencias de ocupacio- 
nes estacionales, caracterizadas por el consumo de productos marinos asociados a fogones y cenizales dispersos, con la recurrente ausencia de restos de cultígenos y cerámica. De otro lado, hacia 1995, Escarcena regresó a Chira-Villa interesado en el estudio de los patrones de subsistencia, pudiendo definir una dieta predominante en recursos marinos con elementos vegetales complementarios y recursos aprovechables de los pantanos próximus de Villa. Ademas, señala que la aparición de la cerámica en este grupo humano no modificó sustancialmente sus patrones alimenticios (Escarcena 1995 y comunicación personal).

Marco teórico y problemática de la investigación

Definimos como Periodo Arcaico en los Andes centrales al lapso de tiempo comprendido entre los 10000 y los 3500 a.p., caracterizado por la adaptación del hombre a condiciones climáticas mas favorables (Período Holoceno), al inicio del proceso de domesticación tanto de plantas como de animales, así como a la aparición de asentamientos complejos, al finalizar este periodo, caracterizados por su arquitectura monumental. De acuerdo con Kaulicke (1999: 11), este periodo puede subdividirse en Arcaico Temprano (10 000-8 500 a.p.), Arcaico Medio (8500-5000 a.p.), Arcaico Tardío (5000-4000 a.p.) y Arcaico Final (4000- 3500 a.p.).

Las estrategias de ocupación que los pescadores arcaicos desarrollaron en la costa central peruana configuran formas de movilidad dentro del territorio, que buscaban la diversidad de ecosistemas, incluidos en las lomas, el valle y el litoral. El concepto de trashumancia -originalmente utilizada para las sociedades pastoriles- o movilidad cíclica no es lo mismo que los "archipiélagos verticales", ni los "sistemas de intercambio" o un patrón de nomadismo sencillo. El patrón de movilidad cíclica consiste en migraciones estacionales de poblaciones 0 parte de ellas a diversos ecosistemas, en una estrategia de subsisten- cia, siguiendo rutas regulares y conocidas (Lumbreras en Lynch,1975: 75). En esta alternancia de ecosistemas no todos los asentamientos que se forman son de igual importancia. Es así que para la presente investigación asumimos esta definición como válida y pertinente para entender el processo de ocupación cultural de la ladera sur del Morro Solar, poniendo énfasis en que la estrategia de este proceso radica en la racionalidad de la explotación de los recursos presentes en los distintos nichos ecológicos de los valles bajos y no necesariamente en las distancias y desplazamiento hacia los ecosistemas, siendo estos últinıos no significativos para el funcionamiento del patrón de movilidad cíclica. De esta forma, en el caso de la costa central peruana, la trashumancia se expresa como un mecanismo de subsistencia de las sociedades arcaicas, quc consiste en una circulación o alternancia cíclica de los grupos humanos en torno a los ecosistemas costeros diferenciados (lomas, humedales, valle y litoral), de marcada estacionalidad. Esta movilidad se realiza dentro de un determinado espacio territorial, donde el grupo se desplaza y logra su subsistencia mediante la explotación de recursos diversos. Por eso, en esta investigación se asume que la movilidad de los habitantes del Conchal San Genaro fue de carácter giratorio y recurrente para la obtención de los recursos que esta zona de captación ofrecía, lo cual no invalida la posibilidaad de su proveniencia desde un asentamiento mayor aún no identificado.

El concepto de movilidad fue empleado por Thomas Lynch (1971) en el estudio de las sociedades tempranas del Perú, a partir de sus investigaciones en el Callejón de Huaylas. Lynch sugirió que las poblaciones de la sierra anualmente se trasladaban a la costa para aprovechar los recursos estaciónales de la época húmeda. Otras evidencias que sugieren el patrón de movimiento de poblaciones hacia la costa, son los 50 sitios que Lanning y Patterson encontraron en las lomas de Ancón (Lanning 1963, Rick 1983) y que demuestran el aprovechamiento de las canteras 
de Chivateros en épocas tempranas. El sitio Cerro Tres Marías (Salcedo, 1997) ubicado en la Tahlada de Lurín, también señalaría la presencia de cazadores serranos asentados en las lomas costeras en campamentos estacionales, quienes se dedicaron a la caza de animales que pacen en las épocas en que estas reverdecen. Este tipo de patrón parece haherse adaptado a la explotación de los recursos que brindahan las lomas durante el invierno, cuando la sierra se encuentra en estación seca y los animales forrajeros descienden hacia la costa en busca de mejores pastos.

\section{Metodología de la investigación}

Metodológicamente se abordó la investigación para determinar el espacio territorial aprovechable para la explotación de recursos por parte de la población que ocupó el emplazamiento del Conchal San Genaro, así como los otros sitios identificados en la ladera Sur del Morro Solar. De la misma manera, se buscó determinar la funcionalidad de estos sitios, así como identificar la economía predominante y la tecnología. Esto nos permitió proponer una secuencia cultural de 5 fases para la zona de determinada Marcavilca (Cuadro 1), que da cuenta del proceso ocupacional Arcaico en la ladera sur del Morro Solar.

En cuanto al proceso de análisis de la secuencia Marcavilca, debemos señalar que ésta no haya explicación únicamente a partir de una lógica evolutiva (ausencia de criterio de superposición), sino que se sustenta en la aplicación adecuada de los principios de superposición, asociación y recurrencia para con cada una de las fases propuestas. Marcavilca I y II se sustentan en la recurrencia de la presencia de asentamientos con ocupaciones pequeñas y medianas, de carácter estacional distribuidas en toda la ladera sur del Morro Solar. Estas evidencias se correlacionan con las encontradas por Medina, Montoya y Hultdwalker en las zonas colindantes a nuestra área investigada. Es decir, se trata de ocupaciones arqueológicas que de manera recu- rrente presentan restos de aves, peces y moluscos consumidos con la relevante ausencia sistemática de cultígenos. Por lo tanto, a pesar de no contar con fechados radiocarbónicos, ni con una superposición estratigráfica directa para esas fases, el patrón recurrente de ubicación, de configuración de estas áreas de quema, su profundidad respecto a la superficie y el recurrente contenido arqueológico identificado que indican su funcionalidad, nos permiten plante:ar de manera tentativa estas dos fases y su relación con las subsiguientes.

La secuencia general planteada tiene un punto central que es la superposición estratigráfica evidente entre Marcavilca III y IV, pero también se sostiene por elementos cornparativos de los materiales asociados; es decir ${ }_{1}$ se utiliza la recurrencia y la asociación (contenido de las capas), donde se observa la presencia y ausencia de los materiales identificados registrados por nuestras investigaciones, los que a su vez han sido también reportados por los investigadores que trabajaron en las zonas aleclañas. De tal manera, se obtienen indicadores diz orden social y cultural significativos que permiten presentar este planteamiento. Metodológicamente, se utiliza el mismo razonamiento para definir Marcavilca $V$, aprovechando la información registrada por Lanning, que presenta una ocupación arqueológica evidenciada por el contenido de las capas registradas aunque con una diferencia sustancial a la registrada por nosotros en San Genaro, por lo que es posible plantear un orden de sucesión factual de la actividad humana durante el período Arcaico en la zona.

\section{El Conchal San Genaro}

La identificación y estudio de El Conchal San Genaro se hizo en el marco dell "Estudio de Evaluación Arqueológica de los A.sentamientos Humanos Nueva Caledonia II, San. Genaro (Sección Oeste) y 26 de setiembre - Chorrillos" (Díaz 1999), que comprendió un área total de 348 $229.48 \mathrm{~m}^{2}$. Para la evaluación del potencial 
Cuadro 1. Cuadro cronológico de la ladera sur del Morro Solar.

\begin{tabular}{|c|c|c|c|c|}
\hline Periodo & Fase & Sitio & Tipo de Establecimiento & Rasgos \\
\hline & Marcavilca I & Ladera Surdel Morro Solar & Estaciones & Fogatas aisladas \\
\hline Arcaico Temprano & Marcavilca II & Ladera Surdel Morro Solar & $\begin{array}{l}\text { Estaciones } \\
\text { Gruposaislados-estacionales }\end{array}$ & $\begin{array}{l}\text { Grandes fogatas reutilizadas sucesivamente } \\
\text { Intrusiones pequeñas }\end{array}$ \\
\hline $\begin{array}{l}\text { Arcaico Medio } \\
(8,500 \mathrm{a} 5,000 \mathrm{a} . \mathrm{P})\end{array}$ & Marcavilca III & Conchal San Genaro & Campamentos aglutinados-estacionales & $\begin{array}{l}\text { Intrusiones grandes y profundas } \\
\text { Capas sucesivas } \\
\text { Áreas mayores con fogones sucesivos } \\
\text { Pocos cultigenos }\end{array}$ \\
\hline $\begin{array}{l}\text { Arcaico Tardio } \\
(5,000 \mathrm{a} 4,000 \mathrm{a} . \mathrm{P})\end{array}$ & MarcavilcaIV & Conchal San Genaro & Aldeapermanente & $\begin{array}{l}\text { Conchal denso } \\
\text { Pocos artefactos } \\
\text { Pocos cultigenos, con prevalencia del algodón }\end{array}$ \\
\hline $\begin{array}{l}\text { Arcaico Final } \\
(4,000 \mathrm{a} 3,500 \mathrm{a} \cdot \mathrm{P})\end{array}$ & Marcavilca V & Chira-Villa & Aldeapermanente & $\begin{array}{l}\text { Conchal denso } \\
\text { Diversidad de artefactos } \\
\text { Variedad de cultigenos }\end{array}$ \\
\hline
\end{tabular}


arqueológico de esta área se realizaron 91 unidades de excavación, de las cuales 22 dan cuenta de la ocupación arqueológic:a del tema de estudio. Quince de estas unidades corresponden a la ladera sur del Morro Solar y dcicumentan básicamente la fase I de la secuencia propuesta. Las 7 unidades de excavación restantes corresponden a la delimitación y estudio de El Conchal San Genaro. La selección de las unidades de excavación presentadas en esta investigación (unidades $12,49,73,74$ y 76$)$, siguen el criterio de representatividad cualitativa del deposito estratigráfico arqueológico estudiado porque documentan factualmente el proceso de ocupación identificado en la zona estudiada y no presentaban alteración moderna. Las unidacles 12 y 49 representan las evidencias arqueológicas más tempranas (Marcavilca I), mientras cue las unidades 73 y 74 dan cuenta de Marcavilca III y IV. Las 15 unida$\operatorname{des}(5,9,12,19,24,25,29,33,39,49,55,59,62$, $64,85)$ que dan cuenta de Marcavilca I presentan la misma estratigrafía, y arrojaron recurrentemente evidencias de delgados lentes de ceniza 0 áreas de quema superficiales con restos de moluscos, huesos de aves y restos de achupallas. Evidencias que son concordantes y complementan las evidencias reportadias por los investigadores Hudtwalker (1997), Medina (2000), Moncoya (1996) y Rea (1997) para los asentamientos colindantes.

A continuación presientamos las evidencias de las unidades excavadas.

\section{Estratigrafia ${ }^{2}$}

UNIDAD 12: Unidad exploratoria de $2 \times 2$ $\mathrm{m}$, que presentó cinco cap̧as donde sólo una capa arrojó evidencias culturales (Fig. 5) La capa A, de arena fina, se encontraba disturbada por las ocupaciones modernas. Tenía $1.10 \mathrm{~m}$ de grosor. La capa $B$, de arena firia con grumos de cal,

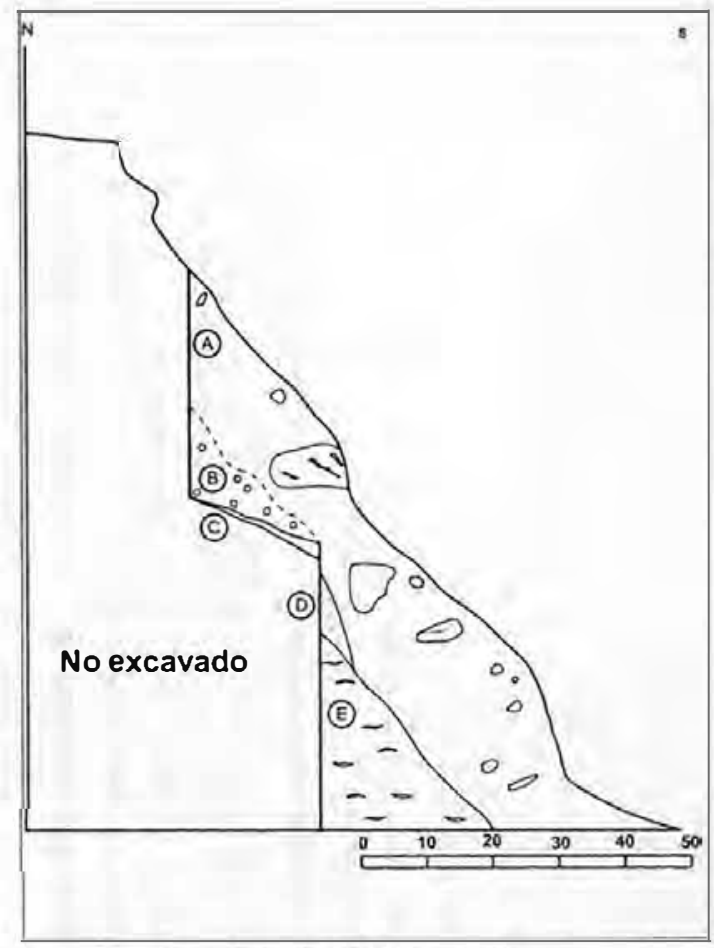

Figura 5. Unidad 12. Perfil este.

poseía $15 \mathrm{~cm}$ de espesor. La capa C presentó concentraciones de cenizas, que correspondían a fogones y áreas de dispersión de los mismos. Es una capa gris oscuro, de $10 \mathrm{~cm}$ y de consistencia semi-compacta. La capa presentó, claramente, un fogón (ceniza más concentrada sobre arena enrojecida), en cuya área de dispersión de cenizas se identificaron concentraciones de pequenas valvas de Choromitylus sp y algunas valvas de Mesodesma donacium. La posición desordenada de las valvas quemadas y la distribución de la ceniza, hacen presumir que se trata de una zona de preparación de alimentos. No se identificaron restos cerámicos ni cultígenos. La capa $D$, de arena fina sin material cultural asociado, es de 15 $\mathrm{cm}$ de espesor. La capa $E$, de arena fina con pequeños grumos y lentes de cal, de $40 \mathrm{~cm}$ de espesor y sin contenido cultural.

- Para una aproximación más decallada de la estratigrafia y de los contenidos de las capas identificadas remitirse al capitulo III (p. 44-63) y A.nexos (102-147) de la tesis. En la sección de los Anexos se presentan los resultados de todos los materiales analizados. 
UNIDAD 49: Unidad exploratoria de 2.80 $\times 2 \mathrm{~m}$, que presentó siete capas donde sólo una de ellas arrojó evidencias culturales (Fig. 6). La capa $A$ es de formación moderna, con $12 \mathrm{~cm}$ de espesor. La capa B, de grosor variable, que alcanza hasta $1.40 \mathrm{~m}$, también es de origen moderno. La capa $\mathrm{C}$ consiste en arena fina mezclada con algunos fragmentos de moluscos (concholepas, Mesodesmas), con un espesor de entre 20 y 40 $\mathrm{cm}$. La capa $D$ es de arena fina y de $25 \mathrm{~cm}$ de espesor. La capa $E$ configura una fogata con su área de dispersión, siendo la ceniza mucho más concentrada en el área misma de la fogata. No presenta piedras que formalicen su contorno, excepto por la presencia de un canto rodado pequeño asociado, al parecer, a un artefacto. Estas características de la asociación le dan una coloración negra o gris oscuro a la capa, la que tiene un espesor de $6 \mathrm{~cm}$ y es de consistencia muy compacta. Los materiales asociados consisten en abundantes fragmentos de huesos, moluscos y el canto rodado mencionado líneas arriba. Se trata de un área de actividad relacionada a la preparación y consumo de alimentos, caracterizada por la abundancia de restos óseos, la mayoría de los cuales (sobre todo de regular tamaño) no pueden recuperarse enteros por la humedad que se ha filtrado al depósito. Esta capa debió extenderse un poco más allá del área detectada, pero fue cortada por un lado por una zanja moderna. La capa $\mathrm{F}$ es de arena mezclada con lentes arcillosos de regular espesor (20 cm de grosor) sin contenido cultural. La capa $G$ es un estrato natural constituido por arena mezclada con arcilla, de $10 \mathrm{~cm}$ de espesor. La capa $\mathrm{H}$ contiene arena y lentes arcillosos, de $84 \mathrm{~cm}$ sin evidencias culturales.

Las evidencias de estas dos unidades de excavación se correlacionan con las evidencias reportadas por Hudtwalcker (1997), Medina (2000), Montoya (1996) y Rea (1997). Ellos dan cuenta de pequeñas áreas de quema con una zona circundante de dispersión de las cenizas, donde sólo se presentan restos de malacofauna, pertenecientes a playas arenosas y rocosas, $y$

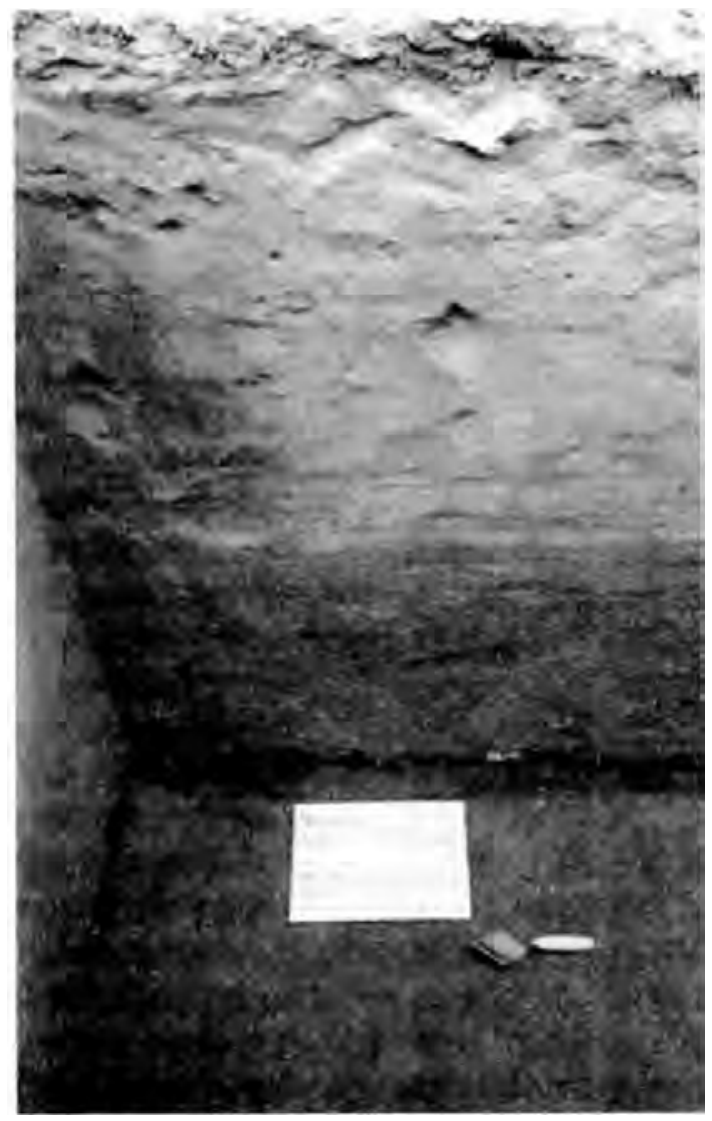

Figura 6. Unidad 49. Vista general del perfil este.

fauna marina. No presenta indicios de superposición estratigráfica, lo que significa una ocupación breve (Rea, 1997). Es recurrente la ausencia de cultígenos asociados.

UNIDAD 73: Se trata de una unidad exploratoria de $2 \times 2 \mathrm{~m}$, que presentaba en superficie evidencias de moluscos fragmentados y ceniza muy mezclados, dándole una coloración cenicienta a la zona (Fig. 7). Aquí se identificaron 7 capas, las que fueron retiradas siguiendo los niveles naturales. La capa $A$, de arena fina y cenizas $\sin$ mas inclusiones naturales, era de $6 \mathrm{~cm}$ de espesor y presentaba evidencias culturales prehispánicas. La capa B corresponde al conchal propiamente dicho en este sector del terreno. Tiene $40 \mathrm{~cm}$ de espesor. Es de coloración gris 
oscuro y de una sedimentación semi-compacta. No es una capa homogénea pues presenta ciertos lentes de color beige o marrón rojizo y algunos bolsones que intruyen la capa subsiguiente. Esta heterogeneidad está causada por la descomposición en forma continua de distintos desechos de actividad doméstica. El material cultural más abundante del cenizal son las valvas de moluscos, en su mayoría Mesodesma donacium (macha), aunque muy fragmentados por el tránsito moderno sobre la zona arqueológica. Además, se identificaron restos de material textil, fragmentos de fibra vegetal, entre otras evidencias. Es una capa que tiene entre 25 y $30 \mathrm{~cm}$ de espesor. La capa $\mathrm{C}$ consiste en un apisonado sobre una capa de arena eólica fina constituyendo un área de actividad inmediatamente subyacente a la capa $B, y^{\prime}$ con evidencias de fogones y un hoyo de poste. Se caracteriza por ser un depósito arcilloso de $4 \mathrm{~cm}$ cuyos materiales asociados consisten en cenizas, moluscos y restos óseos, además del hallazgo de 11 cuentas de concha. La capa Ces la última con evidencia cultural en esta unidad y la

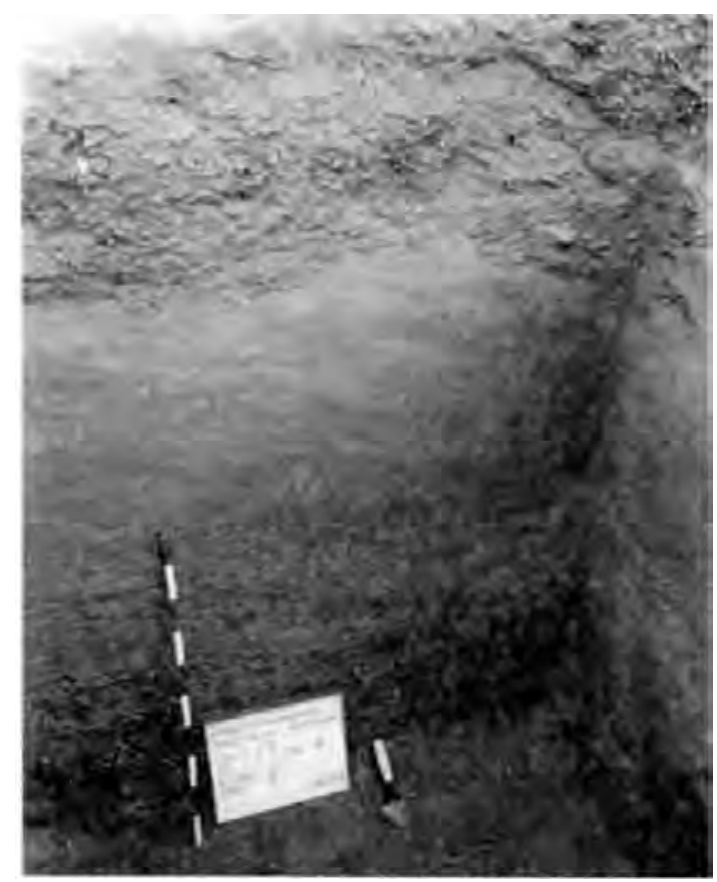

Figura 7. Unidad 73. Vista general del perfil sur. estratigrafía sugiere una ocupación habitacional doméstica (capa C) sobre la que se acumularon los desechos que fueron constituyendo el cenizal (capa B) sin que mediara abandono entre un tipo de ocupación y la subsiguiente. No se encontró evidencias de cerámica. La capa $\mathrm{D}$, es un depósito natural arcilloso de $6 \mathrm{~cm}$ de espesor. La capa $E$ es una capa natural de $65 \mathrm{~cm}$ de espesor, conformada por arena muy fina de carácter eólico. No contiene material cultural. La capa F es un depósito natural de arena eólica, de $30 \mathrm{~cm}$ de espesor. La capa $\mathrm{G}$ es una capa natural de $6 \mathrm{~cm}$ de espesor. La capa $\mathrm{H}$ es de arena eólica de $80 \mathrm{~cm}$ de espesor.

UNIDAD 74: Es una unidad exploratoria de $2 \times 2 \mathrm{~m}$, con evidencias arqueológicas en superficie como moluscos muy fragmentados. El color que adquiere la capa en superficie es grisáceo (Fig. 8). En esta unidad se identificaron 13 capas, de las cuales 7 de ellas tenían contenido cultural. La capa $A$ es de arena que contenía abundante material arqueológico muy fragmentado, mezclado con basura moderna, de $20 \mathrm{~cm}$ de espes.or. La capa B es de arena fina suelta, mezclada con coprolitos de camélidos, de $10 \mathrm{~cm}$ de espesor. La capa C, corresponde al conchal propiamente dicho, con abundantes moluscos fragmentados y algunos enteros (principalmente machas); además de escasos restos vegetales, óseosi animales, etc. Presenta una coloración gris y tiene un espesor de $20 \mathrm{~cm}$. Esta capa cubre la "Intrusión 1" de planta circular que se configura a partir de la capa D. La capa D presenta abundantes moluscos fragmentados y algunos enteros, principalmente machas, acompañadas de algunos restos vegetales, restos óseos, entre otros. Posee mayor cantidad de carbón y' ceniza debiclo a la actividad de preparación de alimentos, lin que hace que sea una capa notablemente más (oscura. Su grosor es de $15 \mathrm{~cm}$ y su consistencia es semi-compacta. Esta capa de conformación horizontal, ha sido cortada por la "Intrusión 1 ", la yue se configura hacia el lado W de la unidad. La "Intrusión 1" intruye las demás capas 


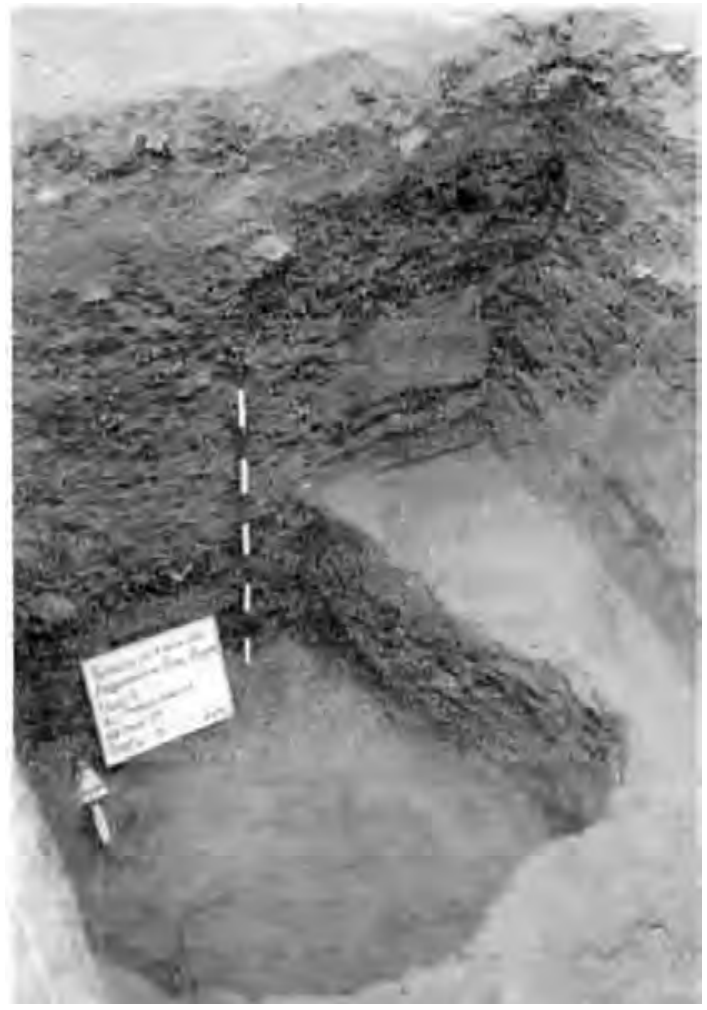

Figura 8. Unidad 74. Vista de la sección NE de la unidad. Se observan las capas de ocupación cultural y' de abandono en este sector del conchal.

horizontales que subyacen a la capa D, configurando una posible "vivienda semi - subterránea" (?). La capa E es de arena mezclada con textiles y ecofactos, de $20 \mathrm{~cm}$ de espesor. La capa $F$ es de arena fina con poco contenido arqueológico y tiene $8 \mathrm{~cm}$ de espesor. La capa $\mathrm{G}$ tiene contenido cultural que fluctúa entre 8 y $12 \mathrm{~cm}$ de espesor. La capa $\mathrm{H}$ es de arena fina suelta y contiene lentes de arcilla. Tiene $8 \mathrm{~cm}$ de espesor y carece de material cultural. La capa I es un estrato natural compuesto únicamente por arcilla, cuyo color es marrón claro, con un espesor de $16 \mathrm{~cm}$, es muy compacta. La capa J consiste en arena fina con múltiples grumos salinos semi-cristalizados. Es de color beige oscuro, dureza de $12 \mathrm{~cm}$ y consistencia semi-compacta. La capa $\mathrm{K}$ es de arena fina depositada por acción eólica, de color beige claro y muy suelta. La capa L es un estrato natu- ral muy compacto compuesto de sales endurecidas que se han mezclado con la arena. La capa $M$ es un deposito natural que consiste en arena fina mezclada con múl tiples grumos arcillosos.

Como se ha indicado, en esta unidad aparece un contexto de características particulares, la "Intrusión 1", que corta los estratos subsiguientes a partir de la superficie de la cap̃a D. Presentó evidencias arqueológicas en los niveles 6,7 y 9 . Este contexto de planta circular irregular parece corresponder a algún tipo de vivienda semi subterránea, aunque no se encontró evidencia clara de esto. Se observa al interior de la intrusión una alternancia de capas arenosas-terrosas con delgados lentes o capas de ceniza con moluscos.

La secuencia estratigráfica presente en esta unidad evidencia diferentes momentos de ocupación sobre el sitio, aunque manten.endo las características generales de la ocupación, es decir, asociados al consumo principal de recursos marinos. La intrusión existente establece mayor complejidad de carácter y tipo de ocupación arqueológica.

UNIDAD 76: Unidad exploratoria de $2 \mathrm{~m} x$ $2 \mathrm{~m}$, donde se registraron 9 capas, siendo 3 de ellas de carácter cultural. La superficie del área muestra un color grisáceo y el terreno es plano. La capa A consiste en arena suelta mezclada con moluscos fragmentados, abunclante basura moderna y $10 \mathrm{~cm}$ de espesor. La capa B es de arena suelta mezclada con coprolitos de camélidos y de $6 \mathrm{~cm}$ de espesor. La capa C consiste en el conchal propiamente definido, que presenta abundantes moluscos fragmentados, vegetales $y$ cenizas. El color predominante es al gris, con un espesur variable de $60 \mathrm{~cm}$ en promedio. La capa $\mathrm{D}$ contiene arena fina acumulada por acarreo eólico, y tiene entre 40 y $50 \mathrm{~cm}$ de espesor. La capa $E$ es también de arena fina pero mezclada con grumos arcillosos dispuestos irregularmente entre 15 a $20 \mathrm{~cm}$. La capa $F$ es un estrato natural compuesto únicamente por arcilla con $18 \mathrm{~cm}$ de espesor. La capa $\mathrm{G}$ consiste en arena fina mezcla- 
da con grumos arcillosos de 20 a $40 \mathrm{~cm}$. La capa $\mathrm{H}$ es un estrato natural compuesto únicamente por tierra arcillosa, de $30 \mathrm{~cm}$ de espesor. La capa 1 consiste en arena fina depositada por acción eólica.

El proceso de ocupación en la ladera sur del Morro Solar

La estrategia de subsistencia desarrollada dentro del proceso de ocupación propuesto radica en la racionalidad de la explotación de los recursos presentes en cada nicho ecológico, al interior del cual las distancias y el desplazamiento que separa a cada zona de recursos no es significativa. Esto queda claramente establecido en el análisıs estratigráfico de las unidades 73 y 74 ubicadas en el Conchal San Genaro, que muestran hiatus (capas culturalmente estériles de origen eólico) en la ocupación cultural. Estas capas son interpretadas como periodos de abandono y desplazamiento a otro nicho. El hecho que los pobladores del "Conchal San Genaro" recurrieran reiteradamente a esce emplazamiento, es indicio de la adecuada ubicación del sitio, próximo a la zona de Pantanos de Villa, las lomas de Villa El Salvador, Atocongo y Tablada de Lurín, los bosques de Chama, las cuencas bajas de los valles de Lurín y Rímac, además de los recursos del mar. Estos nichos hicieron del lugar un área propicia para permanecer y desde allí trasladarse a otras zonas de acuerdo al cambio de las estaciones.

El tránsito desde el Morro Solar hacia los valles de Lurín y Rímac se hace evidente durante las épocas invernales, en la medida que las dunas y pequeñas estribaciones ubicadas en la parte posterior de "Loma de Corvina" y "Amancaes" reverdecen con la baja de temperaturas y" la presencia de una humedad relativa muy alta. Es en esta época del año en que las lomas se convierten en un ecosistema intermedio aprovechable.
El entendimiento de las interrelaciones de los ecosistemas presentes en la costa central, en nuestro caso particular la ladera sur del Morro Solar, nos permiten presentar un esbozo general donde, por su cercanía a el valle de Lurín, nos parece que fue uno de los espacios geográficos más utilizados y visitados por los habitantes arcaicos de esta parte de Lima. Sin embargo, no podemos descartar las rutas hacia el valle del Rimac, en la medida que la estacionalidad costeña no se presenta de manera similar todos los años, más aún cuando los fenómenos de El Niño aparecen cíclicamente. Estas condiciones de inestabilidad climática ocasionan diferencias entre los valles e incluso al interior de los mismos.

Secuencia de las ocupaciones arcaicas del Morro Solar

Urilizando las evidencias arqueológicas registradas por nuestras investigaciones en la zona y las evidencias reportadas por los otros investigadores (Escarcena 1995; Hudtwalker 1997; Lanning 1960; Medina 2000; Monroya 1996; Rea 1997), que también trabajaron en la ladera sur del Morro Solar, hemos podido definir una secuencia cultural para esta zona comprendida en el periodo Arcaico, con las fases Marcavilca I, Marcavilca II, Marcavilca III, Marcavilca IV y Marcavilca V (Cuadro 1), la que presentamos a continuación.

Fase Marcavilca I ${ }^{3}$ (cuadro 2)

No es posible precisar una asignación cronológica clara a esta fase, pero al parecer podría corresponder al Arcaico Temprano. Su segregación en nuestra organización de la información arqueológica estudiada, se basa en la existencia de 4 fogatas aisladas, distribuidas de manera dispersa en toda la ladera sur del Morro Solar, sobre todo entre los sitios Chira-Villa y el Conchal San

\footnotetext{
'La utilización del nombre Marcavilca responde a que, de acuerdo con las fuentes etnohistóricas, este sería el nombre más antiguo del actual Morro Solar.
} 
Cuadro 2. Rasgos de la Fase Marcavilca I.

\begin{tabular}{|c|c|c|c|}
\hline PERIODO. & FASE & $\begin{array}{c}\text { CONTEXTOS } \\
\text { ARQUEOLÓGICOS }\end{array}$ & $\begin{array}{l}\text { TIPOS DE RESTOS } \\
\text { CONSUMIDOS }\end{array}$ \\
\hline \multirow[t]{4}{*}{$\begin{array}{l}\text { Arcaico Temprano } \\
(10000-8500 \text { a.p. })\end{array}$} & \multirow[t]{4}{*}{ Marcavilca I } & $\begin{array}{l}\text { Diaz 1999. Sectores } \\
\text { Nueva Caledonia y San } \\
\text { Genaro; Unidades } 12 \text { y } 49 \\
\text { (además Unidades } 5,9 \text {, } \\
24,25,29,39,49,55,59 \text {, } \\
64,85 \text { ). }\end{array}$ & $\begin{array}{l}\text { Abundantes machas, } \\
\text { escasos choros. Aves } \\
\text { marinas. Muy escasos } \\
\text { restos de peces. Un solo } \\
\text { instrumento litico. }\end{array}$ \\
\hline & & $\begin{array}{l}\text { Hudtwalker } 1997 . \\
\text { Sectores Colinas de Villa. } \\
\text { Perfil Este Jardín I y zona } \\
\text { colindante. }\end{array}$ & $\begin{array}{l}\text { Abundantes machas y } \\
\text { huesos de aves. Un canto } \\
\text { rodado. }\end{array}$ \\
\hline & & $\begin{array}{l}\text { Medina } 2000 \text {. Sector San } \\
\text { Genaro. Unidades } 1,3,11 \\
\text { y } 37 . \\
\text { Montoya 1996. Sector } \\
\text { Colinas de Villa. Perfil } \\
\text { Este Jardin 1. }\end{array}$ & $\begin{array}{l}\text { Moluscos fragmentados y } \\
\text { quemados (almejas, } \\
\text { chanque y erizo), hueso de } \\
\text { ave marina y un resto de } \\
\text { leguminosa. }\end{array}$ \\
\hline & & $\begin{array}{l}\text { Rea 1997. Sector Victor } \\
\text { Raúl Haya de la Torre. } \\
\text { Cateo } 09 \text { - contextos } 1,2 \\
\text { y } 3 \text {. }\end{array}$ & $\begin{array}{l}\text { Abundantes chanques, } \\
\text { escasas machas y muy } \\
\text { escasas lapas. }\end{array}$ \\
\hline
\end{tabular}

Genaro. Estas fogatas o zonas de preparación de alimentos se caracterizan por ser pequeños y del. gados lentes de ceniza negra y blanca, con restos quemados de moluscos enteros y fragmentados, y restos de aves y de peces que fueron cocidos utilizando tillandsias. Suelen ser concentraciones de tamaño variable $(30 \mathrm{~cm}$ a $1 \mathrm{~m})$ sin ninguna formalización estructural. Los moluscos identificados generalmente corresponden a especies de playa arenosa y, en segunda instancia, a las de playa rocosa. Solo en dos casos, en la Unidad 49 reportada por nosotros y en la Unidad 11 reportada por Medina, se encontraron instrumentos líticos elaborados a partir de un canto rodado. Estas evidencias han sido especialmente detectadas en las unidades 12 y 49 en esta publicación, así como en las unidades 5, 9, 24, 25, 29, 39, 49, $55,59,64,85$, también registradas por nosotros. Evidencias similares han sido halladas por Hudtwalker (1997), Medina (2000), Montoya
(1996:31-32) y Rea (1997) para las zonas colindantes. Hay que señalar que es recurrente la ausencia de cultígenos en todos los depósitos registrados tanto por nosotros como por los investigadores mencionados.

$\mathrm{Al}$ parecer, se trataría de pequeños núcleos domésticos aislados, que debieron recolectar los productos de la zona y luego elaboraron las fogatas donde prepararon sus alimentos. La intención de establecer las fogatas en zonas alejadas del humedal podría responder a la abundante disponibilidad de las achupallas (Tillandsias) en la ladera sur del Morro Solar. Por otro lado, esta zona sería mas seca y menos expuesta a los vientos de la playa. Además, mostraría la intención de alejarse de los insectos y mosquitos propios de las zonas húmedas. Nosotros interpretamos estas evidencias como estaciones de pequeños grupos humanos. 
Cuadro 3. Rasgos de la Fase Marcavilca II.

\begin{tabular}{|c|l|l|l|}
\hline \multicolumn{1}{|c|}{ PERIODO. } & \multicolumn{1}{|c|}{ FASE } & \multicolumn{1}{|c|}{$\begin{array}{c}\text { CONTEXTOS } \\
\text { ARQUEOLOGGICOS }\end{array}$} & \multicolumn{1}{|c|}{$\begin{array}{c}\text { TIPOS DE RESTOS } \\
\text { CONSUMIDOS }\end{array}$} \\
\hline $\begin{array}{l}\text { Arcaico Temprano } \\
(10000-8500 \text { a.p. })\end{array}$ & Marcavilca II & $\begin{array}{l}\text { Áreas de quema } \\
\text { Hudtwalker 1997. Nueva } \\
\text { Caledonia. Rasgos 1,2 y } \\
3 .\end{array}$ & $\begin{array}{l}\text { Principalmente machas, } \\
\text { menor proporción de } \\
\text { restos vegetales, restos de } \\
\text { aves y peces pequeños }\end{array}$ \\
\cline { 3 - 4 } & & $\begin{array}{l}\text { Montoya 1996. Nueva } \\
\text { Caledonia. Unidad NC 05. }\end{array}$ & $\begin{array}{l}\text { Machas y chanques } \\
\text { fragmentados, hilo de } \\
\text { algodón. }\end{array}$ \\
\cline { 3 - 4 } & & $\begin{array}{l}\text { Intrusiones } \\
\text { Medina 2000. San } \\
\text { Genaro. Unidades 8, 27, } \\
\text { 49 y 49A. }\end{array}$ & $\begin{array}{l}\text { Machas y chanques } \\
\text { fragmentados y } \\
\text { quemados. }\end{array}$ \\
\hline
\end{tabular}

Marcavilca II (Cuadro 3)

Esta fase tiene una filiación cronológica más clara, correspondiente al Período Arcaico Temprano. En el registro arqueológico se caracteriza por la elaboración de fogatas recurrentes en el mismo lugar, así como por la elaboración de intrusiones en el terreno. Los fogones se superponen, muchas veces cortando e instruyéndose unos a otros. Ambos tipos de ocupación arqueológica aún se presentan de manera dispersa y aislada. A diferencia de la época anterior, se nota una recurrencia en el uso del área, ya que se suceden varios lentes de cenizas que pueden llegar a tener un gran espesor (Montoya, 1996: 23). Esto significaría que se establecen por varios días o semanas, regresando al mismo punto, pero no llegando a configurar un conchal propiamente dicho. Estas concentraciones de cenizas recurrentes tienen formas delimitadas que llegan a tener proporciones mayores a $1.50 \mathrm{~m}$ de largo por $1 \mathrm{~m}$ de ancho o más, con un espesor variable que puede alcanzar en conjunto los $80 \mathrm{~cm}$ ó $90 \mathrm{~cm}$ de grosor. De otro lado, carecen de una formalización estructural que las configure. Otro aspecto característico es la presencia escasa de cultígenos como el algodón. En cuanto a las intrusiones mencionadas, éstas se encuentran registradas por Medina (2000). De acuerdo a estas evidencias, estaríamos ante pequeños campamentos de grupos aislados, que se quedan unos días o pocas semanas en la zona para aprovechar los recursos alli presentes. La acumulación de una estratigrafía recurrente (por lo tanto más compleja y densa) en un solo punto, llegando a conformar fogatas de mayores dimensiones, responde a la presencia de un mayor numero de personas reunidas. A nuestro parecer, esto responde a cambios de orden social, donde los núcleos doméstico encuentran mayor eficiencia en la participación de un mayor número de personas en la obtención de recursos.

\section{Marcavilca III (Cuadro 4)}

Corresponde a la formación de campamentos aglutinados, caracterizados por un aprovechamiento estacional más intensivo de los recursos de la zona, con una alta incidencia en los recursos marinos aunque complementados con los recursos provenientes del valle, así como de las lomas. Esta fase corresponde al Arcaico Medio (8500-5000 a.p.) y, como señalé, se caracteriza por una ocupación estacional, pero con mayores niveles de concentración en la zona de captación. Los grupos humanos son mayores y están explotando no sólo los recursos del mar, sino que definitivamente el proceso de domesticación de plantas está consolidado. Es en este momento que aparece claramente el algodón y el 
mate (Lagenaria siceraria). En un momento final, dentro de esta fase, se incorpora la calabaza $(\mathrm{Cu}$ cúrbita sp) y el frijol (Phaseolus vulgaris) proveniente de la sierra ya en su condición de domesticado. Si bien es cierto que se observa la explotàción de peces pelágicos como la corvina (Cilus gilberti), el bonito (Sarda chilensis), el jurel (Thrachurus murphyi) y escasamente los tollos (Chondrichtyes), la incidencia en peces obtenidos desde la playa es mucho mayor, lo que se expresa en un amplio consumo de la lorna (Sciaena deliciosa)

La estratigrafía arqueológica recuperada en el Conchal San Genaro correspondiente a esta fase se encuentra en las Unidades 74 y 76 de nuestras investigaciones. En estas unidades se observa la alternancia de capas culturales y capas de arena (de abandono) que presentan pocos restos culturales, demostrando la movilidad cíclica del grupo, en una suerte de alternancia de ecosistemas. Los inicios de la fase Marcavilca III, se presentan clatamente en las capas G y D de la Unidad 74. La primera ocupación arqueológica está evidenciada por la capa G (cenizal) y corresponde a un área de preparación de alimentos. Posteriormente, se formó la capa F que corresponde al arenamiento de esa zona y que presenta muy poco contenido cultural (al parecer presen- te allí por arrastre), evidenciando el abandono del lugar. La capa superior, capa E, constituye una deposición de arena con muchos restos vegetales, consumo de peces como la lorna (Sciaena deliciosa), caballa (Scomber japonicus), bonito (Sarda chiliensis), tollo (Chondrichthyes), lisa (Mugil cephalus), corvina (Cilus gilbert) y coco (Paralonchurus p.), aves marinas y un fragmento textil de algodón blanco, representativo de la técnica del entrelazado. Ya que las evidencias de la capa F no están asociadas a una actividad directa de consumo de alimentos, consideramos que las causas de su formación responden al área de dispersión de algún otro punto de actividad cultural cercano. La capa siguiente (capa D) corresponde a la formación de un cenizal producto de la actividad de preparación de alimentos, donde se consumieron peces pelágicos, pero sobre todo bentónicos (lornas). Es en este momento donde aparece la Lagenaria siceraria (mate), aunándose a la utilización del algodón en este yacimiento arqueológico.

Resumiendo, de acuerdo a los productos consumidos, se puede apreciar que el marisqueo de playa es la actividad predominante, junto con el consumo mayoritario de variedades ictiológicas bentónicas como la lorna. De las herramientas

Cuadro 4. Rasgos de la Fase Marcavilca III.

\begin{tabular}{|l|l|l|l|}
\hline \multicolumn{1}{|c|}{ PERIODO. } & \multicolumn{1}{|c|}{ FASE } & \multicolumn{1}{|c|}{$\begin{array}{c}\text { CONTEXTOS } \\
\text { ARQUEOLOGICOS }\end{array}$} & \multicolumn{1}{|c|}{$\begin{array}{c}\text { TIPOS DE RESTOS } \\
\text { CONSUMIDOS }\end{array}$} \\
\hline $\begin{array}{l}\text { Arcaico Medio } \\
8500 \text { - } 5000 \text { a.p.) }\end{array}$ & Marcavilca III & $\begin{array}{l}\text { Capas Ocupacionales, } \\
\text { Conchal San Genaro, U. } \\
74, \text { capas D, E, G. }\end{array}$ & $\begin{array}{l}\text { Presencia de algodón, } \\
\text { calabaza, mate. Peces de } \\
\text { playa y de mar adentro. } \\
\text { Pocas aves. Elaboración } \\
\text { de anzuelo, cuentas. } \\
\text { Tejidos entrelazados. }\end{array}$ \\
\cline { 3 - 4 } & & $\begin{array}{l}\text { Capas de Abandono } \\
\text { Conchal San Genaro. U. } \\
74, \text { capa F. }\end{array}$ & $\begin{array}{l}\text { Escaso. Material } \\
\text { arqueológico de } \\
\text { dispersión. }\end{array}$ \\
\cline { 3 - 4 } & & $\begin{array}{l}\text { Intrusiones } \\
\text { Conchal San Genaro. U. } \\
74, \text { Intrusión 1. } \\
\text { Principalmente machas. }\end{array}$ & $\begin{array}{l}\text { Tillandsias quemadas. } \\
\text { Presencia de algodón, } \\
\text { calabaza, frijol. Consumo } \\
\text { de machas. }\end{array}$ \\
\hline
\end{tabular}




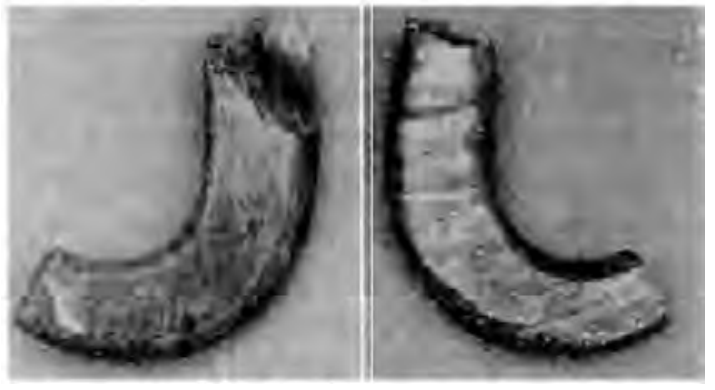

Figura 9. Detalle del anzuelo elaborado en Choromytilus chorus. Medidas: $21 \mathrm{~mm}$ de altura; 18 $\mathrm{mm}$ de ancho.

utilizadas para la pesca, se puede mencionar la presencia de un anzuelc hecho en choro azul (Fig.9) que denota una actividad de pesca individualizada. El empleo del algodón (blanco y marrón) sirvió para la elaboración de los tejidos entrelazados y posiblemente también para hacer redes. La cxistencia del consumo de los mates (Lagenuria siceraria) y diel algodón, muestra el aprovechamiento de los recursos de valle, evidenciando la movilidad hacia los ecosistemas de otros valles, posiblemente el Lurín o el Rímac.

En esta fase también se elaboran grandes intrusiones en el terreno, configurando posiblemente una suerte de "viviendas subrerráneas" sin ningún tipo de paramento que las formalice. Esta posible "vivienula subterránea" está representada por la "Intrusiór l l" de la unidad 74, la que presenta lentes de ceniza en los niveles $6,7 \mathrm{y}$ 9 , los que luego se cubrieron por arena eólica. Es en estos cortos periodos de ocupación que se consumieron productos del valle como la calabaza (Cucúrbita sp) y el frijol (Phaseolus vulgaris). Estas evidencias estarían dandocuenta de la existencia de campamentos de grupos aglutinados que utilizan la zona de acuerdo a como se presentan los recursos según las estaciones marcadas del año.

\section{Marcavilca IV (Cuadro 5)}

El cuarto momento de ocupación en la zona está representado por el propio Conchal San Genaro, donde se evidencian grandes cambios culturales. Es a partir de ese momento que se da una ocupación permanente $y$ un aprovechamiento intensivo de la zona. Esta fase ubicada cronológicamente en el periodo Arcaico Tardío (5000 a 4000 a.p.), se caracteriza por mantener una economía basada en la explotación de los recursos marinos, aunque con una mayor incidencia en los recursos de valle, tanto de la cuenca baja como de la media. Definitivamente, nos encontramus ante una concentración mayor de población, que a partir de este momento no abandonará el asentamiento en la zona. Tecnológicamente se continúa realizando una pesca de mar adentro y de playa, similar a la fase anterior, manteniéndose la popularidad, en cuanto a consumo, de la loma. Es en este momento cuando aparece en el registro arqueológico la pesca del tiburón (Isurnes oxyrinchus). De otro lado, la práctica de la pesca individual se mantiene, ya que no se reporta la presencia de redes, lo que indicaría un cambio social sustancial al convertirse parte de esta labor en una tarea colectiva. La claboración de tejidos en algodón es la misma, sobre todo con el empleo del tejido encrelazado, aunque aparece el empleo del tejido llano.

Esta fase está claramente representada en las evidencias de las capas A, B y C de las unidades 73 y 74 de nuestras excavaciones arqueológicas. Nuestra interpretación de la misma es que corresponde a la formación de las primeras aldeas arcaicas en el área del Morro Solar. Las evidencias de peces perniten inferir la realización de una pesca probablemente realizada desde embarcaciones livianas, actividad que ya se conocería en la fase anterior. Como dijimos, se hace mayor y más complejo el uso del algodón, y a que no solo se le utiliza en los tejidos llanos simples, sino que estos además presentan decoración rep o están teñidos de rojo. Se aprecia la utilización del algodón en las líneas de pesca, aunque también se elaboraron con cabuya (Agave americamus), dato importante si tenemos en cuenta que esta última especie sólo se la encuentra en los valles medios costeros. Un nuevo recurso que se observa en el registro arqueológico es el apro- 
Cuadro 5. Rasgos de la Fase Marcavilca IV.

\begin{tabular}{|c|c|c|c|}
\hline PERIODO. & FASE & $\begin{array}{c}\text { CONTEXTOS } \\
\text { ARQUEOLÓGICOS }\end{array}$ & $\begin{array}{l}\text { TIPOS DE RESTOS } \\
\text { CONSUMIDOS }\end{array}$ \\
\hline \multirow[t]{2}{*}{$\begin{array}{l}\text { Arcaico Medio } \\
(5000-4000 \text { a.p. })\end{array}$} & \multirow[t]{2}{*}{ Marcavilca IV } & $\begin{array}{l}\text { Ocupación Permanente } \\
\text { Conchal San Genaro. U. } \\
\text { 73, capas C, B, A. }\end{array}$ & \multirow{2}{*}{$\begin{array}{l}\text { Presencia de algodón, } \\
\text { técnica textil rep, teñido } \\
\text { del algodón, tejido llano. } \\
\text { Uso de maguey. Cuentas } \\
\text { de concha, consumo de } \\
\text { aves. Pesca de peces de } \\
\text { mar adentro y de playa. } \\
\text { Se registra la presencia } \\
\text { de tiburón. Presencia de } \\
\text { camélidos. }\end{array}$} \\
\hline & & $\begin{array}{l}\text { Ocupación Permanente } \\
\text { Conchal San Genaro. U. } \\
74 \text {, capas C, B, A. }\end{array}$ & \\
\hline
\end{tabular}
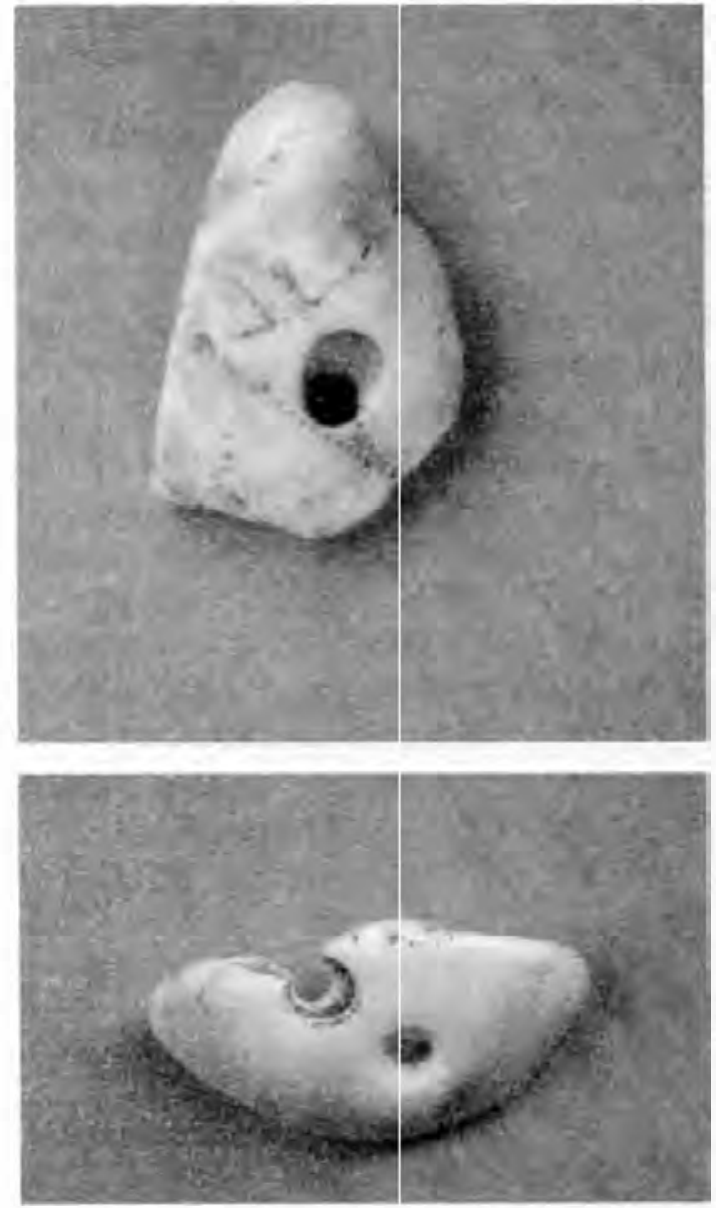

Figura 10. Cuentas recuperadas en las unidades 73 y 74 . vechamiento de camélidos, a decir por los restos óseos (dos vértebras y algunos huesos largos) y abundantes coprolitos encontrados en las capas $\mathrm{A}, \mathrm{B}$ y $\mathrm{C}$ de las unidades 73 y 74 . Esto marca un cambio sustancial en la economía de esta población. De otro lado, se configuran las características iniciales de la especialización del trabajo - tal como lo demuestra la presencia de 9 cuentas elaboradas (Fig. 10) en una concha de caparazón grueso (posiblemente Strombus) proveniente de las aguas norteñas como muestra de la presencia de productos exógenos al área- para la preparación de productos suntuarios. Estas cuentas fueron halladas en asociación a un apisonado arcilloso (capa C de la unidad 73) irrumpido por huecos de poste. Asimismo, se nota una mayor presencia de consumo de aves marinas. La alta presencia de los huesos de aves adultas debe corresponder al consumo total de los pichones de las mismas y no a una preferencia exclusiva de aves adultas. Si bien es cierto, se aprecia claramente la extensa conformación del conchal que pudimos dimensionar en una extensión superficial mayor a los $4000 \mathrm{~m}^{2}$, también llama la atención la inexistencia o escasísima presencia de artefactos como utensilios líticos, espátulas de hueso, piruros y otros tipos de instrumentos. 


\section{Marcavilca V}

Esta fase se encuentra representada fuera del Conchal San Genaro y la ubicamos cronológicamente en el periodo Arcaico Final (4000 - 3500 a.p.). Se la identifica en lus niveles más profundos del sitio Chira-Villa, definida en el compo. nente precerámico Villa (Lanning, 1953: 47). Para esta fase en Chira Villa no se conoce la existencia de entierros ni de algún tipo de arquitectura claramente definida. Únicamente se conoce la existencia de una pequeña porción de muro construido con cantos rodados. Lanning reporta la presencia de textiles entrelazados, redes de algodón, puntas foliáceas de obsidiana, un anzuelo de concha, un piruro de Oliva penuviana, cuentas de Donax, un ornamento irregular de concha con una perforación hacia un extremo, tubos de hueso de aves, muchos chancadores con pigmento rojo, núcleos y un piruro de hueso de ballena. Hay que resaltar que la clara presencia de redes necesariamente denota una pesca de tipo colectiva, marcando cambios fundamentales de orden social. De otro lado, la utilización de la obsidiana revela rutas de intercambio entre regiones muy alejadas, teniendo en cuenta que este material lítico es inexistente en el Conchal San Genaro.

En términos de extensión del yacimiento arqueológico, Chira-Villa es de menores dimensiones que el Conchal San Genaro, pero al parecer igual de denso. Sin embargo, se debe notar que Chira-Villa es más rico en elementos artefactuales. La disminución de su tamaño podría estar indicando un menor número de habitantes, tal vcz debido a que las poblaciones comenzaron a concentrase en los valles, alrededor de los lugares con arquitectura monumental, posibles centros urbanos tempranos, que casi con certeza se ubicaron en el valle de Lurín. Mientras que la abundancia artefactual revela avances en el conocimiento tecnológico y una tendencia a ciertas actividades especializadas. Es en este momento en que la agricultura comienza a prevalecer como actividad económica y de subsis- tencia. Los pobladores de la zona se concentraron en la aldea permanente de Chira-Villa y mantuvieron sus estrategias de explotación y aprove. chamiento del medio marítimo, aún cuando la cerámica se hizo presente en la zona alrededor de los 3500 años a.p. Este material cerámico se conoce como el temprano estilo cerámico Chira, reportado en esta parte de Chorrillos, asî como en la bahía de Ancón (Rosas, 1970: 129). Por lo tanto, esta fase termina con la aparición de la cerámica en el registro arqueológico de las aldeas pescadoras de la zona que corresponden al componente Chira del sitio Chira-Villa (Engel 1957; Lanning 1953; Escarcena 1995), cuya economía se caracterizaría por la abundante presencia de cultígenos, así como una economía también basada en los recursos marinos, y complementada con los que provenían del valle.

\section{Discusión}

El concepto de movilidad o trashumancia como estrategia de subsistencia y de desarrollo cultural para el estudio de los periodos tempranos ha sido poco empleado en la arqueología peruana (Lanning 1963; Lynch 1971, 1975; Macneish, Patterson y Browman, 1975). Sin embargo, su empleo como categoría social resulta muy importante para comprender el aprovechamiento y manejo de los recursos provenientes de ecosistemas diferenciados cercanos, así como de regiones mas o menos distantes, con el objetivo de entender las adaptaciones previas a la complejización social del Período Arcaico.

De acuerdo con Lynch (1971, 1975), la trashumancia estacional en la zona del Callejón de Huaylas se relacionócon los inicios de la agricultura debido a la gradiente de zonas altitudinales de esa región. Por otro lado, considera que la trashumancia se relaciona con un patrón cultural de ocupación de varios ecosistemas y tipo de sitios enel valle del Santa. Lanning (1963: 362), por su parte, sugiere que los sitios ubicados en las lomas de Ancón fueron campamentos invernales de cazadores recolectores provenientes de la sierra, 
y que demuestran el aprovechamiento de las canteras de Chivateros en épocas tempranas. Con lo cual propone una movilidad entre las zonas de cordillera y la planicie costera, especialmente en la época invernal. Consideramos que esta interpretación de la información arqueológica otorga un rol trascendental al ecosistema de lomas en el desarrollo cultural de las sociedades arcaicas vecinas, tanto de la costa como de la sierra, en la medida que las sitúa como zonas de confluencia cultural y social entre espacios geográficos diferenciados. Con una interpretación similar, Salcedo (1997), a partir de sus investigaciones en el sitio Cerro Tres Marias, Tahlada de Lurín, define la presencia de cazadores serranos (Tradición Lauricochense) en las lomas de Lurín, quienes se asentaban en campamentos estacionales en las lomas costeras de este valle. Por su parte, Macneish, Patterson y Browman (1975) enfocan sus investigaciones en la región de Ayacucho. Huanta, a partir de reconstruir las esferas de interacción prehispánicas en la región. Ellos proponen que para el período Arcaico el patrón de asentamiento se compone de campamentos estacionales (invierno, otoño, primavera, verano) de micro bandas que se trasladan de las zonas altas donde se realiza la caza, a zonas de valle interandino para efectuar la recolecta de plantas, una agricultura estacional y la domesticación del cuy.

La costa peruana durante el período Arcaico, representó un difícil ambiente para la conformación de grandes grupos poblacionales, salvo algunos sitios que de manera particular y quizás por razones muy propias de la zona del asentamiento, han presentado altu niveles de densidad poblacional o de utilización del espacio para establecerse (caso Paloma y en menor medida la ladera sur del Morro Solar). Por otra parte, un hecho que si parece ser recurrente, debido a lo difícil del medio, es la ubicación de los asentamientos en diferentes zonas o ecosistemas próximos y complementarios para la subsistencia humana, en una estrategia de ocupación que parece alternarse de manera cíclica y estacional.
Por otra parte, el mar peruano, favorecido con la presencia de la corriente de Humboldt, determina las temperaturas frías de la costa y las condiciones de humedad que propician el crecimien to de las lomas invernales. Esto hace posible la presencia importante de mamíferos y aves marinas, lo que ha permitido condiciones más o menos estables para la obtención de recursos propicios para la subsistencia humana a lo largo del tiempo.

De esta manera, podemos señalar que la estrategia de subsistencia corresponde a tres factores fundamentales de los ecosistemas arcaicos de la costa peruana: 1) el carácter estacional de los ecosistemas que sólo permite su aprovechamiento por un periodo determinado de tiempo, 2) el carácter limitado de estos ecosistemas para proporcionar los recursos alimenticios (proteínas animales, vegetales) que garanticen la subsistencia por un tiempo prolongado y, 3) el carácter igualmente estacional de los recursos marinos disponibles, limitados a algunas especies según el desarrollo tecnológico.

Son estos tres factores principales los que condicionan la dispersión de los asentamientos durante el periodo Arcaico Temprano y Medio entre los 10000 años a.p. y los 5000 años a.p. Un hecho que es común en estos períodos es especialmente la existencia de un medio natural con fuertes limitaciones, pero que también es explicable o comprensible por el nivel tecnológico de las sociedades del Arcaico, pues es claro que en economías donde predomina la caza, la recolecta y la extracción marina del litoral, los niveles o posibilidades de obtención de recursos son sumamente escasos y condicionados a la estacionalidad de los ecosistemas.

Si nos atenemos a las investigaciones geológicas y paleoambientales desarrolladas, las cuales señalan un período geológico de homogeneidad climática posterior al "optimun climático", la costa peruana ha presentado, en términos generales, las mismas condiciones de desertización y sequedad que actualmente conocemos. Por ello, 
el posterior desarrollo de las sociedades arcaicas no parecen responder a variantes climáticas, sino que pueden ser entendidos a partir de sus innovaciones tecnológicas y sus niveles de especialización productiva, así como de un desarrollo en la complejización social que experimentaron estos grupos humanos antes del Arcaico Final (4000-3500 a.p.), precisamente durante el tránsito del Arcaico Medio al Tardío, donde los asentamientos comienzan a ser ocupados por poblaciones más densas y principalmente de mayor duración o estabilidad ocupacional en el mismo sitio. En otras palabras, las técnicas de obtención de recursos alimenticios evolucionan a una mejor utilización de un ecosistema específico, en nuestro caso el ecosistema marítimo, lo que se complementa con productos provenientes de otros ecosistemas, como la utilización del algodón para las actividades de pesca y caza, y también el vestir.

Como consecuencia de cllo, con el advenimiento del Arcaico Tardío (5000-4000 a.p.) y el Arcaico Final (4000-3500 a.p.) las poblaciones se sedentarizan, lo que conlleva a un decrecimiento fundamental de la movilidad cíclica de los grupos humanos entre ccosistemas estacionales. Con el surgimiento de la arquitectura monumental durante el Arcaico Final se denotará especialmente los inicios de la diferenciación social basada en elementos de orden teocrático, de acuerdo con las evidencias de algunos sitios como Huaca Prieta, El Ásperoy Caral.

Estableciendo la correlación del Conchal San Genaro y el proceso cultural sucedido en la falda sur del Morro Solar con otros sitios contemporáneos, podemos apreciar marcadas diferencias con los asentamientos de pescadores arcaicos del sur, y similitudes con aquellus asentamientos prehispánicos de la costa nor-central en el valle de Huarmey.

Los asentamientos de pescadores arcaicos de la costa sur peruana, tales como El Anillo (Richardson et al. 1990), Quebrada Jahuay (Sandweiss et al. 1999), Quebrada Tacahuay (Keefer et al. 1998) y Quebrada de los Burros (Lavallé et al, 1999), al parecer se desarrollaron desde el Arcaico Temprano. En términos de: proceso podemos notar la marcada especialización de estos grupos en la explotación de los recursos del mar, determinando sus estrategias de rnovilidad a lo largo del litoral. Las investigaciones arqueológicas en estos sitios presentan diferentes énfasis en los recursos provenientes del mar (ver Cuadro 6), relacionados a los recursos más disponibles en cada zona. En El Anillo existe una predominancia en el consumo de peces y luę, o de aves. En Quebrada Jahuay se da un consumo balanceado entre peces, crustáceos y mioluscos. En Quebrada de los Burros predomina el consumos de moluscos complementado con peces, mientras que en Quebrada Tacahuay lia dieta se sustenta en el consumo preferente de aves. Todos los artefactos y otros elementos identificados en estos 4 sitios dan cuenta de una tecnología muy especializada en la pesca y caza marina, además que eventualmente están realizando caza de animales terrestres como camélidos y' cérvidos, de acuerdo a lo reportado por Lavallé (1999: 45) en Quebrada de los Burros. Es interesante notar que en ninguno de los casos se reporta la presencia de cultígenos ni instrumentos que señalen su aprovechamiento, lo que podría deberse a condiciones de conservación. En todo caso, esta ausencia es muy congruente con la caracterización de grupos humanos de pescadores especializados registrados en el extremo sur del Perú y costa norte de Chile para en épocas coloniales y posteriores, conocidos como el grupo étnico los Changos, altamente especializados en la explotación del mar.

Procesos similares al identificado en la ladera sur del Morro Sular en Chorrillos, son reportados por Bonavia en la zona de Huarmey. Alli, él identifica una secuencia de 5 momentos, siendo los 4 últimos de ellos comparabless con nuestra zona de trabajo. El proceso de ocupación en Huarmey se inicia en el segundo momento de esa secuencia (Arcaico Medio). Aquí se reporta el 
Cuadro 6. Recursos aprovechados y tecnología productiva de los sitios tempranos del litoral sur de la costa peruana.

\begin{tabular}{|c|c|c|c|c|c|c|c|c|}
\hline & Perlodos & Tipodeasen lasileato & Dleta & Cultigenos & recnieas decaptura & Trenicalertil & Insirumentos liticos & Instrumentodellueso \\
\hline San Genaso & $\begin{array}{l}\text { A. Modio } \\
\text { A. Tardio }\end{array}$ & $\begin{array}{l}\text { Conechal ubicado en una } \\
\text { Isderade susvependiente, } \\
\text { a2 kmdelaplays }\end{array}$ & Marina & $\begin{array}{l}\text { Algoston, fifijol. } \\
\text { salabsaz, manl. }\end{array}$ & $\begin{array}{l}\text { Lincessise pescay anzuelo } \\
\text { (loma). Pesced deorillay } \\
\text { conposibleembarcación }\end{array}$ & $\begin{array}{l}\text { Enirelazsdo. } \\
\text { Rep.iliano }\end{array}$ & $\begin{array}{l}\text { Ausencia de puntas. } \\
\text { presencin de chascadores }\end{array}$ & $\begin{array}{l}\text { Arzuelode conchalchoro), } \\
\text { cuent as deconcha, conchas modificsdas }\end{array}$ \\
\hline Chin Villa & A. Final & $\begin{array}{l}\text { Conchalubicando en una } \\
\text { bodm de fuencependientc. } \\
20.8 \mathrm{kmdel} \text { mar. }\end{array}$ & Mavina & Algatson & Radesde algodsh & Ennurlacaso & $\begin{array}{l}\text { Puntas de priyectillolescoss. } \\
\text { puntas deobsidians. } \\
\text { chane adopes. núcleos }\end{array}$ & $\begin{array}{l}\text { Anzuclo de concha, cuentus deconchas (donax). } \\
\text { cuentuas de ave, piruso deeone bay de huess de bal lens }\end{array}$ \\
\hline $\begin{array}{l}\text { ElYacht } \\
\text { Club }\end{array}$ & $\begin{array}{l}\text { A.Tanlio } \\
\text { A. Final }\end{array}$ & $\begin{array}{l}\text { Conchalen un promuntorio } \\
\text { corea dela playa }\end{array}$ & Marino & 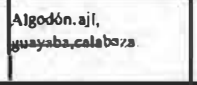 & $\begin{array}{l}\text { Rodes dealgodon, ilineade } \\
\text { pesca conanzuelosy } \\
\text { resusustepesca }\end{array}$ & ? & ? & Anzuelo deconchas \\
\hline L.s Pampa & $\begin{array}{l}\text { A Modio } \\
\text { A Tandto }\end{array}$ & $\begin{array}{l}\text { Conchslen piomonioizo } \\
\text { rocosoceres de la playa }\end{array}$ & Marina & Calabazas & $\begin{array}{l}\text { Lineasdepeses, an zueloy } \\
\text { pesosuepesse }\end{array}$ & $\begin{array}{l}\text { Sogay de Junco. } \\
\text { Nohayalgodon }\end{array}$ & Lascas & Anzuelo de concha, euentas de hives o de a vey conchas \\
\hline Lapaloma & A. Madio & $\begin{array}{l}\text { Aldeaubicadaen } x 0 \text { ns } \\
\text { te lomas a } 4 \text { bundellitoral }\end{array}$ & \begin{tabular}{|l|} 
Marina \\
(Alamiferos \\
maninos, $96 \%)$
\end{tabular} & Calabazens, mates & $\begin{array}{l}\text { Lineasdepesca con an zuclo, } \\
\text { Pesces deotillayc: } \\
\text { on embarcacion }\end{array}$ & $\begin{array}{l}\text { Anilladudoblecon } \\
\text { conchitascocidas }\end{array}$ & $\begin{array}{l}\text { Puntas se proyectil foliaceas, } \\
\text { chancadores, instumentusde } \\
\text { moler }\end{array}$ & Auzuclos de concha, cuenlas deconelia \\
\hline Chilcs & $\begin{array}{l}\text { A.Medio } \\
\text { A. Turdio } \\
\text { A.Final }\end{array}$ & $\begin{array}{l}\text { Conchal ubicado hascia } \\
\text { lamatgen Nortedel Irio } \\
\text { Chilka, a } 7 \text { Kmdel Litoral }\end{array}$ & Maring & 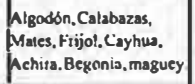 & $\begin{array}{l}\text { Redesde algoddn, lineas } \\
\text { de pescacunpeans } \\
\text { compuestas, eon puias }\end{array}$ & Usode algosion & $\begin{array}{l}\text { Purtasdeproyectil } \\
\text { lanceuledas }\end{array}$ & Conc has modificadas, espiculasdehuesso \\
\hline Anillu & $\begin{array}{l}\text { A. Temprano } \\
\text { A. Medio } \\
\text { A. Tandio }\end{array}$ & $\begin{array}{l}\text { Circulo de restiosde moluscos a } \\
\text { con depresión central. } \\
\text { ubicados } 0.75 \text { koridelmas. }\end{array}$ & $\begin{array}{l}\text { Matina } \\
\text { (Predominanpoces, } \\
\text { luegoaves) }\end{array}$ & ? & $\begin{array}{l}\text { Usade anzucloycordel. } \\
\text { Pescedeorilla }\end{array}$ & Nosepresisa & 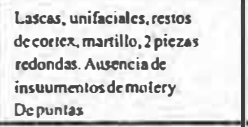 & Anzuelocompuesto, aTón, conchasmodifica das \\
\hline Oosahuary & $\begin{array}{l}\text { A. Temprano } \\
\text { A Medio } \\
\text { A. Tardio }\end{array}$ & $\begin{array}{l}\text { Conchal cercadel Liloral, a } 2 \mathrm{~km} \text {. } \\
\text { delaplays }\end{array}$ & Marina & $\begin{array}{l}\text { Peces, coustibcosy } \\
\text { monluscos. } 96.5 \%)\end{array}$ & ? & 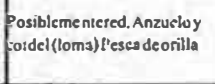 & Cuerdas anudadas & 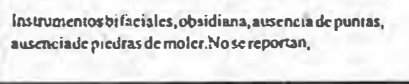 \\
\hline O Tacahwery & $\begin{array}{l}\text { A Temprano } \\
\text { A. Medio }\end{array}$ & $\begin{array}{l}\text { Conchalcercadel litoral, a } 04 \mathrm{~km} \text {. } \\
\text { Detaplaya }\end{array}$ & $\begin{array}{l}\text { Marina } \\
\text { (Psocesamien lode } \\
\text { aves,99.8\%) }\end{array}$ & ? & $\begin{array}{l}\text { Redesde pesca } \\
\text { (anchovetas) }\end{array}$ & 3 & $\begin{array}{l}\text { Dos instrumentos, una } \\
\text { herramienta, } 17 \text { lascas. } \\
\text { Instrumentosuniy bitaciales. }\end{array}$ & 4 \\
\hline $\begin{array}{l}\text { Quebiale de } \\
\text { Los Burnas }\end{array}$ & $\begin{array}{l}\text { A.Temporso } \\
\text { A. Medio A } \\
\text { Tardio }\end{array}$ & $\begin{array}{l}\text { Comechalcerco all hitoral, asociado } \\
\text { al trabajode lallalltica }\end{array}$ & $\begin{array}{l}\text { Marins } \\
\text { (Predominanlos moluscos, } \\
\text { complementusoconpeces) } \\
\text { otills ypecsa con } \\
\text { Embatececión }\end{array}$ & ? & $\begin{array}{l}\text { Lincas de pesca con anzuelo: } \\
\text { ypesas, uso deaupon, usode } \\
\text { puntas de dos tipos, Pesca de }\end{array}$ & ? & $\begin{array}{l}\text { Lascas, desechus de talla. } \\
\text { esquirlas, unifaciales, bifaciales, } \\
\text { chasticadores, puntas. }\end{array}$ & 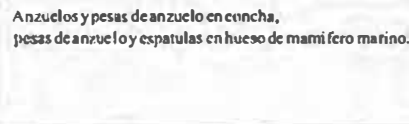 \\
\hline
\end{tabular}

"Fuente: Benfer, 1982, 1984, 1986; Engel, 1957, 1963, 1980, 1987, 1988; Escarcena, 1995; Glendon et al, 1988; Kecfer et al, 1988; Lanning, 1960,1963, 1967; Lavallée et al, 1999; Sandweiss et al, $1998,199 a, 199$ b". Esta línea está en el cuadro original. 
sitio PV 35-106 (Bonavia 1996: 172-176) consistente en un asentamiento al aire libre, de ocupación permanente. Los pobladores de este asentamiento sededican sobre todo a la actividad del marisqueo de playa rocosa, búsqueda de bulbos y raíces, así como al aprovechamiento de mates y calabazas. En el tercer momento de ocupación arcaica en la zona de Huarmey, momento de transición hacia la Época 2 de los Gavilanes, se registra el sitio PV35-6 que también corresponde al Arcaico Medio. Este asentamiento permanente aprovecha las plantas alimenticias cultivadas (Bonavia 1996: 176-177), como la palta, el frijol, la calabaza, el mate y el algodón. Su industria lítica es casi inexistente, ya que sólo se utilizan lascas. Los moluscos marinos predominantes son los de playa rocosa. Los peces son poco consumidos al igual que las aves. En cuanto a las técnicas textiles desarrolladas, se señalan los tejidos entrelazados y las redes. El siguiente momento en Huarmey esta representado por la Época 2 definida en los Gavilanes, donde además de los productos encontrados en la fase anterior se suman la achira, el maní, la yuca, la guayaba y el ají, siendo notoria la aparición del maíz. En la Éroca 3 se incorporan otros cultígenos como la chirimoya, la jiquima, el pallar y tal vez el camote. En estos dos momentos se continuó haciendo gran uso de los moluscos, sobre todo de la concha de ahanico. Hay una disminución del consumo de lobos, junto con un aumento en el aprovechamiento de las aves y peces. La fauna terrestre fue a escala menor, aunque la gran cantidad de presencia de coprolitos de camélidos muestra su uso a lo largo de estas tres ultimasépocas.

En términos generales, en Huarmey se observa un proceso de sedentarización más temprano que en Chorrillos. Mientras que en el sitio PV35-106 las poblaciones están establecidas de manera permanente, durante la fase Marcavilca III en Chorrillos estas permanecen sólo por ciertas estaciones en la zona. La permanencia en el Morro Solar se iniciará durante el Marcavilca IV. Sin embargo, este proceso continuará cada vez más enriquecido con la presencia de nuevos productos cultivados durante los siguientes periodos de ocupación descritos por Bonavia en Huarmey. En términos de la movilidad o trashumancia, se aprecia en Huarmey una relación cada vez mayor con los ecosistemas del valle, sobre todo para la obtención de los productos cultivados, mientras que a la vez va disminuyendo la dependencia de los recursos marinos. Este proceso de alejamiento del mar, como factor fundamental en las economías arcaicas en Huarmey, culmina en el Arcaico Final, durante la Época 3 de los Gavilanes. Si en el proceso de adaptación de los grupos de pescadores-agricultores incipientes de la costa central, el mar jugó un rol importante en un principio, fueron el conocimiento y aprovechamiento de las plantas los que les permitieron echar las bases para la formación de las primeras sociedades complejas.

\section{Conclusiones}

Nuestras investigaciones en la ladera sur del Morro Solar nos permiten señalar la existencia de una larga ocupación cultural de la zona durante el Periodo Arcaico. Esta ocupación del Arcaico define un complejo cultural al que hemos denominado Marcavilcal, cuyas poblaciones aprovecharon los ecosistemas de humedal, del mar, lomas y valle presentes en la costa central peruana. Esta explotación de recursos se configuró como una estrategia de subsistencia consistente en un patrón de movilidad o trashumancia cíclica, que respondía a la estacionalidad de los ecosistemas locales presentes (Fig. 11). La movilidad se realizaba tanto en un eje longitudinal a lo largo del litoral marino, como en un eje transversal, que los llevaba a ingresar a los valles costeros próximos, en este caso el valle de Lurín y del Rímac. En las fases más tempranas del Complejo Marcavilca se percibe la preponderancia de una economía sustentada básicamente en la explotación de los recursos marinos. Durante el Arcaico Medio se incorporan algunos recursos de valle que mejoran las condiciones de la pesca 


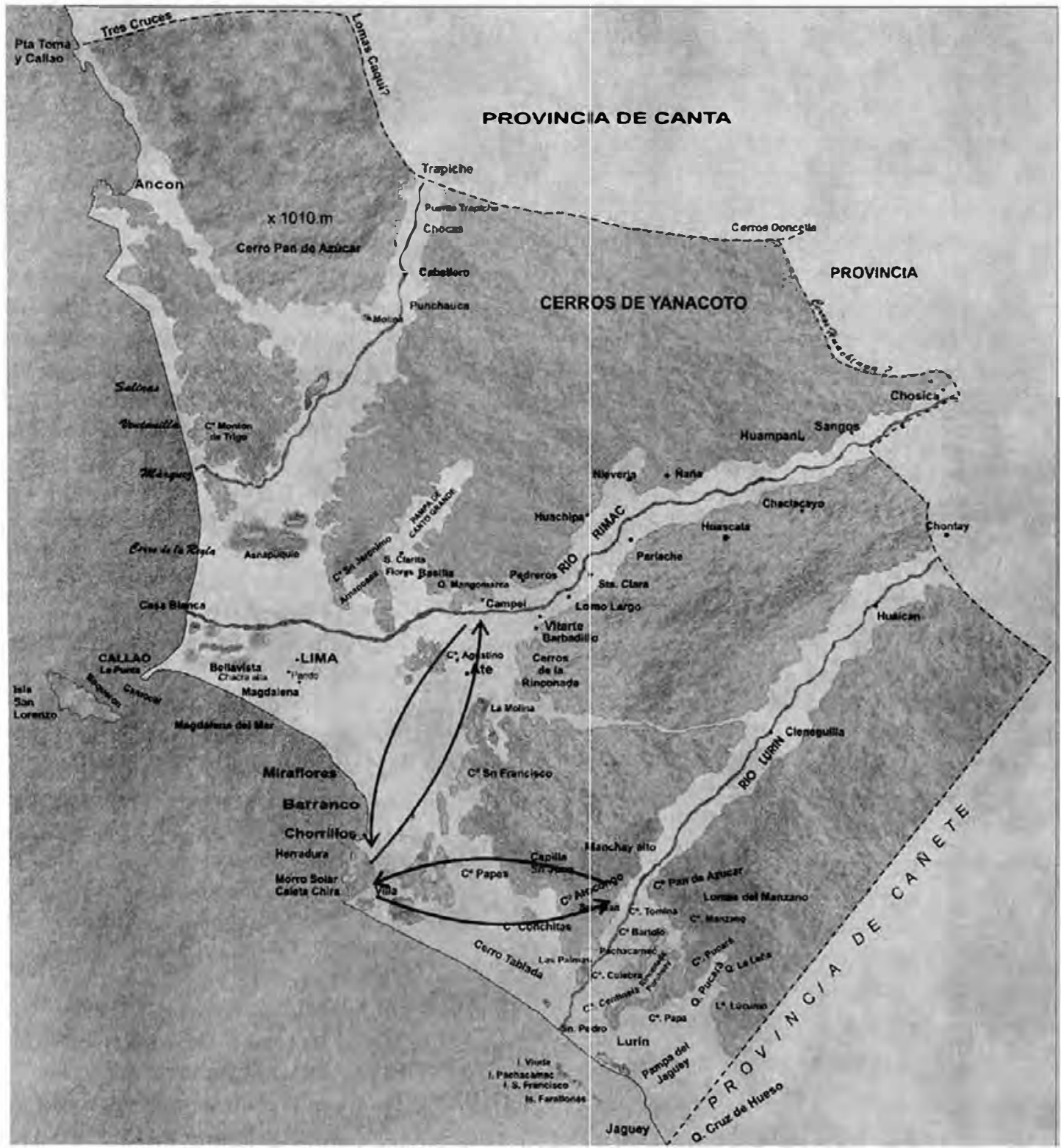

Figura 11. Área geográfica donde se desarrollo el Patrón dè Movilidad Cíclica de las poblaciones arcaicas Del Morro Solar.

y la caza en el ecosistema marítimo. Durante el Arcaico Tardío y Final, esta economía paulatinamente se va haciendo más dependiente de los cultígenos, determinando cambios hacia una economía diversificada y productora, y más dependiente de las especies cultivadas en el valle. La incorporación paulatina pero mayoritaria de cultígenos en la vida cotidiana de estas poblaciones arcaicas, marcará el cambio en el patrón de movilidad grupal cíclica entre los ecosistemas costeros. Pasarán así de un régimen de trashumancia grupal y estacional, durante el Arcaico 
Temprano y Medio, hacia el establecimiento permanente de grupos poblacionales en el Morro Solar, dando origen a las primeras aldeas en la zona. A la luz de la información publicada, podemos señalar que el área de Chorrillos tuvo un proceso cultural particular y diferenciado, donde se aprecia que tanto los habitantes de El Conchal San Genaro, como los de El Anillo, Quebrada Jahuay, Quebrada Tacahuay y Quebrada de los Burros, comparten una tecnología similar en cuanto a la obtención de los recursos marinos, mas no así en cuanto a la explotación y manejo de cultígenos como los observados en el Conchal San Genaro. Todo parece indicar que este proceso de movilidad cíclica entre los ecosistemas de mar, valle y lomas costeras se dio sobre todo en la costa central y nor-central, como en la zona de Huarmey. De esta manera, las poblaciones arcaicas asentadas en este espacio geográfico tuvieron mayores posibilidades de desarrollar una economía mixta y no especializada como sus contemporáneos del sur. Esto creó las condiciones para que durante el Arcaico Tardío los establecimientos del valle comenzaran a cobrar mayor importancia a raíz de la aparición de la agricultura en la costa, de tal manera que las relaciones de dependencia entre estos ecosistemas cambiaron, tornándose los asentamientos de valle paulatinamente más importantes. Este proceso permitió pasar de una organización aldeana incipiente a la conformación de las primeras sociedades complejas.

\section{Bibliografía}

Aldenderfer, Mark

1990 "Asana: un yacimiento arcaico al aire libre en el sur del Perú". En Trabajos arqueológicos en Moquegua, Perú, Vol. I, pp.91-104.

1990 "Cronología y definición de fases arcaicas en Asana Sur del Perú". Chungará № 24/25, Universidad de Tarapacá, Chile.

1999 "Comunidades Andinas Pre-Tribales: Los orígenes de la diversidad". En Historia de América Andina, Vol 1. Las
Sociedades Aborigenes. Universidad Andina Simón Bolivar.

Benfer, Robert

1982 "El Proyecto Paloma de la Universidad de Missouri y el Centro de Investigaciones de Zonas Aridas". Zonas Aridas, Vol. 2, CIZA. Universidad Nacionalde LaMolina. Lima.

1984 "The Challenges and the Rewards of Sedentism: The Preceramic Village of Paloma, Perú”. En Cohen y Armelagos (eds.). Paleopathology at the Origins of Agriculture, pp. 531-558. Nueva York.

1986 "Holocen coastal adaptations: Changing demography and health at the fog oasis of Paloma, Perú 5,000-7,000 B.P." En Matos, M., R., Turpin, S.A., and Eling, H.H., Jr. (Eds.). Andean Archaeology, Papers in Memoir of Clifford Evans, pp. 45. 64. Institute of Archaeology Monograph 27. University of California, Los Angeles.

Bird, Junius

1948 "Preceramic Cultures in Chicama and Virú". En Bennett, Wendell C. (Ed.). A Reappraisal of Peruvian Archaeology, pp. 21-29. Memoirs of the Society for American Archaeology 4. Vol. 13, N ${ }^{2}$ 4,2. Menosha, Wisconsin.

1949 "Los más antiguos agricultores de América". Revista del Museo Regional de Ica, №1, pp. 3-15. Ica.

Bird, Junius B., John Hyslop y Skinner Milica

1985 "The Preceramic Excavations at The Huaca Prieta, Chicama Valley, Perú". The American Museum of Natural History Anthropological Papers, 62 (1). New York

Bittman, Bente y J, Munizaga

1984 "Evolución en poblaciones precolombinas de la costa norte de Chile". Clıngará, № 13. Universidad de Tarapacá, Arica.

Bonavia, Duccio

1982 Los Gavilanes. Preceramico peruano: mar, desierto y oasis en la historia del hombre. Corporación Financiera de Desarrollo e Instituto Arqueológico Alemán. Lima. 
1996 "De la caza-recolección a la agricultura: una perspectiva local". Boletin del Instituto Francés de Estudios Andinos, 25 (2): 169 186. Lima.

Cano, A.; M.l., La Torre; B. León; K. Young; J. Roque \& M. Arakaki

1999. "Estudio comparativo de la flora vascular de los principales humedales de la zona central del departamento de Lima, Perú". En K. Young \& A. Cano (eds.). Los Pantanos de Villa, Biología y Conservación. Serie de divulgación N 11.

Cardich, Augusto

1958 "Los yacimientos de Lauricocha. Nuevas interpretaciones de la Prehistoria Peruana". Acta Prehistórica, Vol. 2, pp. 1 65. Buenos Aires.

1964/6 "Lauricocha Fundamentos para una Prehistoria de los Andes Centrales". Acta Prehistorica, Vol. 8/10, № 1, pp. 3 171. Buenos Aires.

De Niro, Michael

1988 "Marine Food Sources for Prehistoric Coastal Peruvian Camelids: Evidence". Econonic Prehistory of the Central Andes. BAR International .Series 427

Díaz Arriola, Luisa

1999 "Estudio de evaluación arqueológica de los A.A.H.H. Nueva Caledonia II, San Genaro (Sección Oeste) y 26 de Septiembre - Chorrillos". Lima. INC.

2005 "Estrategias de ocupación del litoral durante el Arcaico Medio y Tardío: el Conchal San Genaro". Tesis para optar el grado de Magister en Arqueología Andina. Unidad de Post-grado de la Facultad de Ciencias Sociales de la UNMSM, Lima.

Engel, Frederic

1957 "Sites et établissementes sans ceramique de la côte peruvienne". Joumal de la Sociéte des Americanistes, 46. París.

1958 Algunos datos con referencia a los sitios precerámicos de la Costa Peruana. Lima.

1963 "A Preceramic Settlement on the Central Coast of Perú: Asia, Unit l". Transactions of the American Philosophical
Society, Vol.53, Part 3. Philadelphia.

1980 Prehistoric Andean Ecology. Man, Settlement an Environmert in the Andes. Archivos del Centro de linvestigación de Zonas Aridas (CIZA) Universidad Nacional Agraria. Lima.

1987 De las Begonias al Malz. Vida y Producción en el Perú Antiguo. Centro de Investigaciones de Zonas Aridas (CIZA) Universidad Nacional Agraria, La Molina. Lima.

1988 Chilca, Pueblo 1. Implementos de Hueso: Ecologia Prehistórica Andina. El Hombre, su establecimiento y el Aimbiente de los Andes. La Vida en las Tierras Aridas y Semi-aridas. Centro de investigaciones de Zonas Aridas (CIZA $A_{1}$ Universidad Nacional Agraria, La Molina. Lima

Escarcena, Augusto

1995 Proyecto Arqueológico Morro Solar: ChiraVilla. Informe Temporada 1994-1995, Lima. Documento presentado al INC.

Feldman, Robert

1984 "Early Textiles from the Supe Valley, Perú". Conference on Andean Textiles, April 7th and 8th, 1984. The Textiles Museums, Washington, [1.C.

Fung, Rosa

1970 Informe de hallazgos arqueológicos en la parte baja del valle de Lurin. UNMSM. Lima.

Glendon, Weir; Robert Benfery JohnG. Jones

1988 "Preceramic to Early Formative Subsistence on the Central Coast". Economic Prehistony of the Central Andes.

Grieder, Terence

BAR International. Serie:; 427.

1984 "Preceramic and Initial Period textiles fron La Galgada, Perú". Conference on Andean Textiles April 7th and 8th, 1984. The Textile Museu:m Washington, D.C.

Hudtwalcker, José Antonio

1997 Evaluación arqueológica en los $\mathrm{AAHH}$ Nueva Caledonia l y Colinas de Villa distrito de Chorrillos, Lima. Lima. Documento presentado al INC. 
Kaulicke, Peter

1999 "Los estudios del Período Arcaico en el Perú: logros, problemas y propuestas." Boletin de Arqueología. El Periodo Arcaico en el Peru: Hacia una definición de los orígenes. PUCPN 3 . Lima.

Keeper, D. K., et al.

1998 "Early Maritime Economy and El Niño Events at Quebrada Tacahuay, Perú". Science, Vol. 281, p. $1833-1835$

Lanning, Edward P.

1960 "Chronological and Cultural Relationships of Early Pottery Styles in Ancient Perú". Tesis Doctoral, inedita. Universidad de California.

1963 A Pre-agricultural Occupation on the Central Coase of Perú. American Antiquity, Vol. 28, pp. 360-371.

1967 Peru, Before the Incas. Prentice-Hall, Inc., Englewood Cliffs, New Jersey.

Lavallée, Daniele; Michele Julien; Philippe Bearez; Pierre Usselmann; Michel Fontugne Y Aldo Bolaños

1999 "Pescadores-recolectores Arcaicus del extremo Sur Peruano". Boletín del Irstituto Francés de Estudios Andinos, 28 (1): 1352.

Lynch, Thomas

1971 "Preceramic transhumance in the Callejón de Huaylas, Perú". American Antiquiry. Journal of the Society for American Archaeology, Vol. 36, $\mathrm{N}^{\circ} 2$.

1975 "La cosecha inoportuna, trashumancia y el proceso de domesticación". Estudios Atacameños, № 3: 75-80. Universidad del Norte, Museo de Arqueología, San Pedro de Atacama, Chile.

1980 "Guitarrero Cave. Early Man in the Andes". Estuclies in Archaeology. Nueva York.

1989 "Regional interaction, transhumance. and verticality: archaeological use of Zonal Complementarity in Perú and Northern Chile". En Michigan Discissión in Anthropology, Vol. 8, pp. 1-11. Ann Harbor. Massachussets.
Macneish, Richard; Thomas Petterson y David Browman

1975 The Central Peruvian Prehistoric Interaction Sphere. Papers of the Robert S. Peabody Foundation for Archaeology. Massachusetts.

Medina, Ada

2000 Estudio de Evaluación Arqueológica en los AA.HH San Genaro (Sección Este) y Villa Venturo, Chorrillos. Informe Final. INC. Lima.

Miller, Alberto

1986 "Economic Prehistory at the Ancón Tank Site: A Test of Demoghraphic Explanations of Agricultural Origins in the Ancón Chillón Region Central Peruvian Coast". Dissertation for the Degree of Doctor of Philosophy in Anthropology. State University of New York at Binghamton.

Montoya, Huayta

1996 Evaluación arqueológica en colinas de Villa y Nueva Caledonia-Chorrillos - Dpto. Lima". Lima, INC. Documento presentado al INC.

Muñoz Ovalle, lván

1982 "Las sociedades costeras en el litoral de Arica durante el Período Arcaico Tardío y sus Vinculaciones con la Costa Peruana". Chungará, 9: 124-151; Arica, Universidad de Tarapacá.

Quilter, Jeffrey

1986 "Las Economías de Subsistencia y los Orígenes de las Sociedades Andinas Complejas". Boletin de Lima, № 46, 15 . 25. Lima

1991 "Late Preceramic Peru".Joumal of World Prehistory, Vol. 5, NN24,p. 387-438.

Rea, Carlos

1997 "Informe de Evaluación Arqueológica del Asentamiento Humano "Ilustre Maestro Víctor Raúl Haya de La Torre", Distrito de Chorrillos, Provincia de Lima, Lima". Documento presentado al INC. 
Reitz, Elizabeth

1988 Preceramic Animal Use on the Central Coast. Economic Prehistory of the Central Andes. BAR International Series 427.

Richardson III, James B. "Looking in the Right Places: Pre 5000 B.P. Maritime Adaprations in Peru and the Changing Environment". Revista de Arqueologia Americana №15.

Richardson III, James B.; Daniel Sandweiss; Robert Feldman et al

1990 "Tempranas Adaptaciones Marítimas en los Andes". En Trabajos Arqueológicos en Moguegia, Peru, Vol. 1, p. 139-176. Programa Contisuyo del Museo Peruano de Ciencias de la Salud. Southern Perú Conper Corporation.

Rick, John

1983 Cronología, Clima y Subsistencia en el Precerámico Penuano. Colección Minima. Indea. Lima

Rosas, Hermilio

1970 "La Secuencia Cultural del Período Formativo en Ancón". Tesis para optar el grado de Bachiller en Arqueología. Presentada a la UNMSM. Programa Académico de Psicología y Ciencias Sociales. Departamento de Ciencias Histórico Sociales. Sección Arqueología. Lima.

Salcedo C., Luis E.

1997 "Excavaciones en Cerro Tres Marías (Valle de Lurin): Un Campamento Temporal del Período Arcaico en la Lomas de Atocongo" Tesis para optar el titulo de Licenciado en Arqueología. Facultad de Letras y Ciencias Humanas. PUC.

Sandweiss, Daniel; H. Mc Innis; R. Burger; A. Cano; B. Ojeda; R. Paredes; M. del C. Sandweiss y M.D. Glascock

1998 "Quebrada Jaguay: Early South American Maritime Adaptations". Science, Vol.281, p. $1830 \cdot 1832$

Sandweiss, Daniel; David Keefer, James Richardson III

1999a "First Americans and the Sea". Discovering Archaeology, Jan/feb. El Paso.
Sanclweiss, Daniel; Asunción Cano; Barnardino Ojedla y José Roque

19(99b "Pescadores Paleoindios del Perú". Investigación y Ciencia, Octubre, p. 55 61.

Serpar- Lima

1998 Área de Protección Nunicipal Pantanos de Villa. Refugio de Vida Silvestre. Centro de Interpretación Pantanos de Villa.

Uhle, Max

1906 "Los Kjoekkenmoedding del Perú". Revista Histórica, Tomo I, Primer Trimestre, p. 3-23

1918 "Los Aborigenes de Arica". Revista Histórica, Tomo VI, Entrega I. Lima.

1919 "Fundamentos Étnicos de la Región de Arica y Tacna". Boletín de la Sociedad Ecuatoriana de Estudios Históricos Americanos, Vol. II, №4.

1931 Las Antiguas Civilizaciones de Manta. Quito.

1970 (1908) "Las civilizaciones primitivas en los alrededores de Lima". En 100 de Arqueologia en el Peni. IEP. Lima.

Usselmann, Pierre; Michel Fontugne, Danièle Lavallée, Michel Julien y Christine Hatté

1999 "Estabilidad y Rupturas Dinámicas en el Holoceno de la Costa Surperuana: El Valle de la Quebrada de los Burros (Departamento de Tacna)". Bulletin de línstitut Francais d'Etudes Andines, Tomo 28, № 1. IFEA, Lima.

Ziolkowski, Mariusz S. et al.

19194 Andes. Radiocarbon Ducabase for Bolivia, Ecuador and Peru. Andean Archaeological Mission of the Institute of Archaeology, Warsaw University and Gliwice Radiocarbon Laboratory of the Institute of Physics, Silesian Technical University. 